NBER WORKING PAPER SERIES

\title{
ESTIMATING NETWORK ECONOMIES IN RETAIL CHAINS: A REVEALED PREFERENCE APPROACH
}

\author{
Paul B. Ellickson \\ Stephanie Houghton \\ Christopher Timmins \\ Working Paper 15832 \\ http://www.nber.org/papers/w15832
}

\author{
NATIONAL BUREAU OF ECONOMIC RESEARCH \\ 1050 Massachusetts Avenue \\ Cambridge, MA 02138 \\ March 2010
}

The authors would like to thank Arie Beresteanu, Tim Bresnahan, Jeremy Fox, Tom Holmes, Shakeeb Khan, and Andrew Sweeting for their helpful comments. We have also greatly benefited from the thoughtful suggestions of participants in the NBER Winter IO Meetings, Duke University Applied Microeconometrics Lunch, the Minnesota Applied Micro Workshop, the Triangle Econometrics Conference, and seminar participants at Rochester, Texas A\&M, Texas-Austin, Wisconsin, Virginia Tech, and the Yale SOM. Any remaining errors and omissions are our own. The views expressed herein are those of the authors and do not necessarily reflect the views of the National Bureau of Economic Research.

NBER working papers are circulated for discussion and comment purposes. They have not been peerreviewed or been subject to the review by the NBER Board of Directors that accompanies official NBER publications.

(C) 2010 by Paul B. Ellickson, Stephanie Houghton, and Christopher Timmins. All rights reserved. Short sections of text, not to exceed two paragraphs, may be quoted without explicit permission provided that full credit, including $\odot$ notice, is given to the source. 
Estimating Network Economies in Retail Chains: A Revealed Preference Approach

Paul B. Ellickson, Stephanie Houghton, and Christopher Timmins

NBER Working Paper No. 15832

March 2010

JEL No. L0

\begin{abstract}
$\underline{\text { ABSTRACT }}$
We measure the effects of chain economies, business stealing, and heterogeneous firms' comparative advantages in the discount retail industry. Traditional entry models are ill-suited for this high-dimensional problem of strategic interaction. Building upon recently developed profit inequality techniques, our model admits any number of potential rivals and stores per location, an endogenous distribution network, and unobserved (to the econometrician) location attributes that may cause firms to cluster their stores. In an application, we find that Kmart and Target benefit most from local chain economies; Wal-Mart's advantage is more global. We explore these results with counterfactual simulations highlighting these offsetting effects.
\end{abstract}

Paul B. Ellickson

Simon School of Business Administration

University of Rochester

Rochester, NY 14627

paul.ellickson@simon.rochester.edu

Stephanie Houghton

Texas A\&M University

TAMU 4228

College Station, TX 77843-4228

houghton@econmail.tamu.edu
Christopher Timmins

Department of Economics

Duke University

209 Social Sciences Building

P.O. Box 90097

Durham, NC 27708-0097

and NBER

christopher.timmins@duke.edu 


\section{Introduction}

Over the past few decades, "big box" chain stores have come to dominate many sectors of retail trade. While the chain store format dates back to the early 1900s, the "big box" phenomenon is more recent, relying on the diffusion of the automobile and the great American migration to the suburbs. Just as the much larger supermarket format replaced corner grocers in the 1950s, "big box" superstores replaced smaller "mom n' pop" sporting good, book, and hardware stores in the 1980s and 1990s. The leading example is Wal-Mart, which alone accounted for $9.6 \%$ of U.S. retail sales in 2008, excluding automobile and gasoline sales. In the discount retail sector specifically, Wal-Mart, Kmart and Target now comprise threequarters of total sector sales and show few signs of slowing down. The chain store advantage is both national and local: chains take advantage of scale economies in purchasing and logistics, as well as more local "density" economies that arise from sharing local knowledge and pooling advertising resources. Despite the increasing dominance of chain superstores, there is relatively little empirical work quantifying the size and sources of the chain advantage. ${ }^{1}$ This is the goal of our paper.

In part, the lack of empirical research reflects the scale and complexity of the chain store's decision problem: building a massive network of outlets and distribution centers that move products to consumers as efficiently as possible, recognizing that their rivals are doing the same. Until recently, a complex strategic game on such a high dimensional space was thought impossible to solve, much less estimate. ${ }^{2}$ Furthermore, many retail sectors are dominated by as few as two or three firms, begging the question of how one can recover rich systems of parameters with the observed behavior of so few players. Building on the profit inequalities approach developed by Pakes et al. (2006) and Bajari et al. (2007), we propose a scalable empirical framework for analyzing network entry problems that does not require solving for an equilibrium, or even that the equilibrium be unique or played in pure strategies. Rather, it simply requires enforcing the equilibrium condition that the observed choices yield higher expected payoffs than any feasible alternatives, holding rivals' actions

\footnotetext{
${ }^{1}$ Jia (2008) and Holmes (2008) are two notable exceptions, discussed in detail below. Earlier, Smith (2004) applied discrete choice demand estimation to analyze mergers between supermarket chains.

${ }^{2} \mathrm{Jia}$ (2008) exploited the lattice structure of a two-firm game to reduce the computational burden of solving for equilibria, while Fox (2007) and Bajari and Fox (2009) use the tools of maximum score and revealed preference to avoid solving for choice probabilities at all.
} 
fixed. We apply our estimator to the discount retail sector, isolating the comparative advantages of each of the three players and quantifying the relative importance of the local chain effect. Moreover, given the relative simplicity of our estimation approach, this framework could easily be applied in other multi-store or multi-product settings such as airline hub and spoke networks or automobile product line decisions.

Our empirical framework builds on the profit inequalities (henceforth, PI) framework developed in Pakes et al. (2006) and Bajari el al. (2007), incorporating the pairwise maximum score approach to large scale decision problems proposed by Fox (2007) and implemented by Bajari and Fox (2009). Rather than attempting to fully solve a complex discrete game for empirical choice probabilities that are then matched to data ${ }^{3}$, the PI approach relies on a revealed preference argument that involves comparing actual choices to a large set of counterfactual actions that each firm could have chosen. Since the actual decisions arose from equilibrium play, these counterfactual choices must be payoff reducing, creating a large set of profit inequalities on which to base estimation. By relying on profit inequalities rather than equilibrium choice probabilities, the PI approach avoids solving for equilibria, mitigating concerns over multiplicity and eliminating the need to impose (or estimate) a selection rule. It also places relatively weak restrictions on the content of player's information sets, allowing for (but not requiring) asymmetric or incomplete information. This simplified structure makes the framework scalable: it can handle any number of players, subject only to memory and data constraints. In contrast to the alternative choice probability framework, a complex choice space works to the advantage of the PI approach, providing more inequalities with which to pin down parameter estimates.

In practice, we consider a large number of "local" perturbations to the observed chainnetwork structure that involve swapping pairs of stores owned by rival firms between matched pairs of markets. Along with creating the profit equalities on which we base estimation, this swapping of matched pairs serves a second purpose: eliminating any com-

\footnotetext{
${ }^{3}$ This is the approach utilized in the "generalized discrete choice" (Pakes (2008)) framework proposed by Tamer (2003) and extended by Ciliberto and Tamer (2009), Andrews, Berry, and Jia (2004), and Beresteanu et al. (2009). In these settings, partial identification often obtains due to the possibility of multiple equilibria: the model can only provide bounds on the range of permissible choice probabilities. Alternatively, the researcher can impose or estimate a selection rule to restore point identification (Bajari, Hong, and Ryan (2009)), although this still requires solving for all the equilibria. Partial identification can also arise in the PI framework if certain support conditions do not hold. These conditions are discussed in detail below.
} 
mon sources of unobserved market heterogeneity. In particular, by considering only matched swaps of rival stores between pairs of markets, these difference-in-difference inequalities allow us to eliminate a common, market-level unobservable, which is key to obtaining unbiased estimates of local chain and competition effects. Because we control for the structural error in this way, and because the markets from which stores are swapped are chosen randomly, the profit inequalities satisfy a rank-ordering property and can be estimated using pairwise maximum score (Fox (2007)), a conditional median inequality analog of the moment inequality methods utilized by Pakes et al. (2006).

Intuitively, the PI approach exploits the complexity of the decision space to offset the small number of market participants noted above. Even though the number of players is small (in this case three), the number of possible alternative configurations (and pairwise deviations) is immense, allowing us to exploit asymptotics in the number of choices, rather than the number of agents. However, the small number of players does impose a cost when it comes to recovering and decomposing the fixed effects that dropped out of the differencein-difference inequalities. Doing so is critical for using the parameter estimates to learn about marginal effects of specific common drivers of firm behavior (e.g., population) or for simulating counterfactual equilibria resulting from a change in the underlying primitives. Employing another set of inequalities, based this time on the first order conditions from the profit maximization problem, we recover ranges in which these fixed effects can lie, and then project them onto additional covariates using set inference techniques developed by Beresteanu and Molinari (2008). Set identification follows from the limited number of inequalities available given the small number of players observed in this industry.

We apply our estimator to the store location choice problem faced by Wal-Mart, Kmart, and Target. Treating the decision of where (and how many stores) to locate in each of 1351 markets as a static discrete game, we find that each firm has individual preferences and unique strengths. Consistent with conventional wisdom, we find that Wal-Mart favors rural locations and Target more urban settings, with Kmart in between. We find that Wal-Mart imposes the strongest competitive pressure on its rivals, followed by Target and then Kmart. Notably, to offset the presence of an additional rival firm, Kmart requires an increase in market population that is 25-35 percent greater than the size of the increase required for Target or Wal-Mart. More subtly, we find that Kmart and Target benefit the most from 
local scale economies, the elimination of which would cause each firm to exit 522 and 35 markets respectively. While Wal-Mart would also suffer from the elimination of these local chain effects, the impact is much smaller, suggesting that their advantage is more global in nature.

Our paper builds on and extends the static entry literature that started with Bresnahan and Reiss $(1990,1991)$ and Berry $(1992) .{ }^{4}$ We also contribute to a growing literature on WalMart itself, which includes Basker (2005, 2007), Hausman and Leibtag (2005), Neumark, Zhang, and Ciccarella (2008), and Zhu, Singh, and Manuszak (2009).

While most authors have focused on isolated entry decisions by single-product firms, the first structural papers to address the chain store network problem directly are Jia (2008), Nishida (2008), and Holmes (2008). Jia (2008) examines the strategic store placement decisions of Kmart and Wal-Mart, using a full solution method that exploits a supermodular representation of the two-player game. Her elegant, lattice-based solution mechanism comes at a cost, restricting her analysis to only two national players and requiring that the net chain effects be non-negative (i.e. that business stealing not outweigh the benefits of agglomeration). She models network economies as positive spillovers occurring across nearby locations (defined as counties), inferring the chain effect from the extent to which firms cluster their own stores. However, she is only able to consider counties that contain a single store per firm. Nishida (2008) extends Jia's approach to allow any number of stores to be placed in a location, but requires the model to exhibit positive spatial spillovers across locations and can only accommodate two competing firms. Both approaches require imposing an equilibrium selection rule prior to estimation. Our analysis relaxes these restrictions, so that we may consider the full set of potential locations, allow for any number of competing firms, and place no restrictions on the number of stores per location or the net impact of spatial spillovers. We are also able to control for proximity to endogenously placed distribution centers and remain agnostic with regard to equilibrium selection.

Holmes (2008) examines the spatial structure of Wal-Mart's national network from the perspective of dynamic discrete choice, using Wal-Mart's sequential decisions over where to

\footnotetext{
${ }^{4}$ Other notable papers include Mazzeo (2002), Tamer (2003), Seim (2006), and Ackerberg and Gowrisankaran (2006). Zhu and Singh (2009) and Zhu, Singh, and Manuszak (2006) use a discrete game approach to examine entry by Wal-Mart, Kmart and Target, but ignore the network aspects of their entry decisions.
} 
open additional stores to infer the importance of economies of density. In particular, the degree to which Wal-Mart passed up early entry into desirable locations to build additional stores closer to a distribution center reveals their preference for such proximity. Holmes also incorporates information on store-level revenues, further identifying density economies from the extent to which Wal-Mart tolerates cannibalization of sales by its own nearby stores. However, in acknowledging the dynamic aspects of Wal-Mart's decision process, Holmes does not model (or control for) reactions to (or by) Wal-Mart's rivals.

Like Jia, we abstract from the dynamics of the chain problem to focus on strategic interaction. ${ }^{5}$ However, in contrast to both Jia and Holmes, our identification strategy turns on the degree to which firms prefer to face another one of their own outlets rather than an additional outlet of a rival.

As noted above, our framework draws heavily upon the profit inequality approach developed by Pakes et al. (2006) and Bajari el al. (2007). We extend their analysis, however, by employing set estimation techniques to recover and decompose the error component which is differenced out of the profit inequalities. Doing so is critical for recovering the full drivers of firm behavior and performing subsequent counterfactuals. Our first-stage estimation procedure uses the pairwise maximum score method of Fox (2007), but is closer in structure to Bajari and Fox (2009), who consider competitive bidding for packages of mobile phone "spectrum" licenses. The application in Bajari and Fox is similar to ours in that it involves an extremely high-dimensional choice problem. It differs in that they are able to re-cast their problem as a one-to-many two-sided matching game, whereas our problem retains the features of a standard entry model with endogenous competitive agglomeration and own-business stealing effects.

The remainder of this paper proceeds as follows. Section 2 presents details about the data and provides background on the discount store industry, which motivates our modeling and estimation approach. Section 3 presents a model of firm profit as a function of the attributes of markets where they place their stores. We then outline a three-part estima-

\footnotetext{
${ }^{5}$ While the dynamic aspects of retail competition are clearly important, incorporating them into a strategic model of competition is greatly complicated by the non-stationary structure of the discount store industry. Wal-Mart has never exited a market and Kmart hasn't opened a new store in over six years. While there are some signs that the industry has stabilized in recent years, the available data currently reflect the process of expanding to equilibrium, as opposed to the ergodicity of a stationary Markov process. See Beresteanu and Ellickson (2006) for an attempt to address some of these issues.
} 
tion algorithm used to recover these payoff functions. In the first stage, we estimate the strategic components of store-level profits via pairwise maximum score. In the second and third stages, we recover set-valued estimates of the common, market-level fixed effect and decompose that fixed effect to estimate the remaining components of firm profit. Section 4 presents the empirical results and further explores their implications by applying them to a counterfactual scenario in which the positive benefits of clustering chain stores are removed. Section 5 concludes.

\section{The Discount Store Industry}

While the segment of retail now served by chain discount stores was once quite fragmented, in the past few decades it has come to be dominated by three main players: Wal-Mart, Kmart, and Target. While each firm is essentially national in scope, there are some fairly obvious distinctions in the types of markets they choose to serve, partly driven by the types of consumers they target. Consistent with its rural beginnings and choice of merchandise, Wal-Mart favors rural locations and smaller cities, avoiding the largest cities almost completely (not always by choice). Target, on the other hand, prefers urban locations, consistent with its trendier, "up-market" focus. Finally, Kmart is somewhat less focused, having stores both in major cities and rural towns. In addition to proximity to consumers, location choice is also constrained by logistical concerns - stores have to be stocked with merchandise from a regional distribution center, and so may benefit from being close to that hub and close to one another. These economies of density may also come in the form of shared advertising, shared local market knowledge, and managerial spillovers between stores in the same market. All three firms balance these economies of scale and density against the idiosyncratic preferences of individual consumers by designing an optimal network of stores.

Before verifying these stylized facts and motivating our specific modeling choices, we first introduce our dataset and choose a sensible definition of a "local market". In retail industries, location choice essentially dictates the types of consumers you are going to serve, as individuals tend to sort themselves into reasonably homogeneous neighborhoods. While such sorting could (and probably does) occur on a very local level, from the researcher's perspective, there is a trade-off between choosing a fine geographic grid and obtaining mean- 
ingful demographic covariates. With this trade-off in mind, we chose Core Based Statistical Areas (CBSAs) as our basic building block, which we will call a market or location. CBSA refers collectively to metropolitan statistical areas and smaller "micropolitan" statistical areas. Firms choose which locations to enter and how many stores to build in each. While this coarse-grained market definition ignores more nuanced aspects of spatial differentiation, it allows us to account for correlated, market-level unobservables, which are key to correctly identifying network and competition effects. In addition to these local characteristics, an important determinant of store location choice is the distance to suppliers, which we capture using detailed information on distribution centers unique to our dataset.

The data on discount stores are drawn from the Trade Dimensions Retail Tenant Database for 2006. Both the dataset and the construction of local markets are described in detail in Appendix A. Figure 1 illustrates the locations of all the discount stores in our data set, along with the locations of all distribution centers. Target's tendency to cluster in urban locations is clear, providing a sharp contrast with the more uniform distribution of Wal-Mart and Kmart locations. Figure 2 focuses in on the upper Midwest, bringing this contrast into sharper focus. Note that Target tends to place distribution centers close to large cities, which is consistent with supporting its generally accepted upscale, urban focus. Wal-Mart, on the other hand, places its distribution centers so as to best serve stores which are themselves located in the interstices between major markets.

Overall, Wal-Mart has a presence in $97 \%$ of these markets, compared to $44 \%$ and $26 \%$ of the markets for Kmart and Target, respectively (see Tables 6 and 7 in Appendix A). In part, this is expected because there are more than twice as many Wal-Mart stores included in the data (3345) as there are Kmart or Target stores (1362 and 1443, respectively). However, it also appears that these firms follow quite different strategies when locating stores. This is illustrated clearly in Table 7, which summarizes the location characteristics for each store. Over $95 \%$ of Target's stores are located in metropolitan statistical areas, compared to only $68 \%$ of Wal-Mart's stores and $78 \%$ of Kmart's stores.

Finally, Figure 3 examines the relationship between the number of discount stores located in each market and population. The top left panel, which is in levels and includes the fitted regression line from a simple quantile (median) regression, reveals that the relationship is fairly linear, at least up until the very largest markets (Los Angeles and New York 

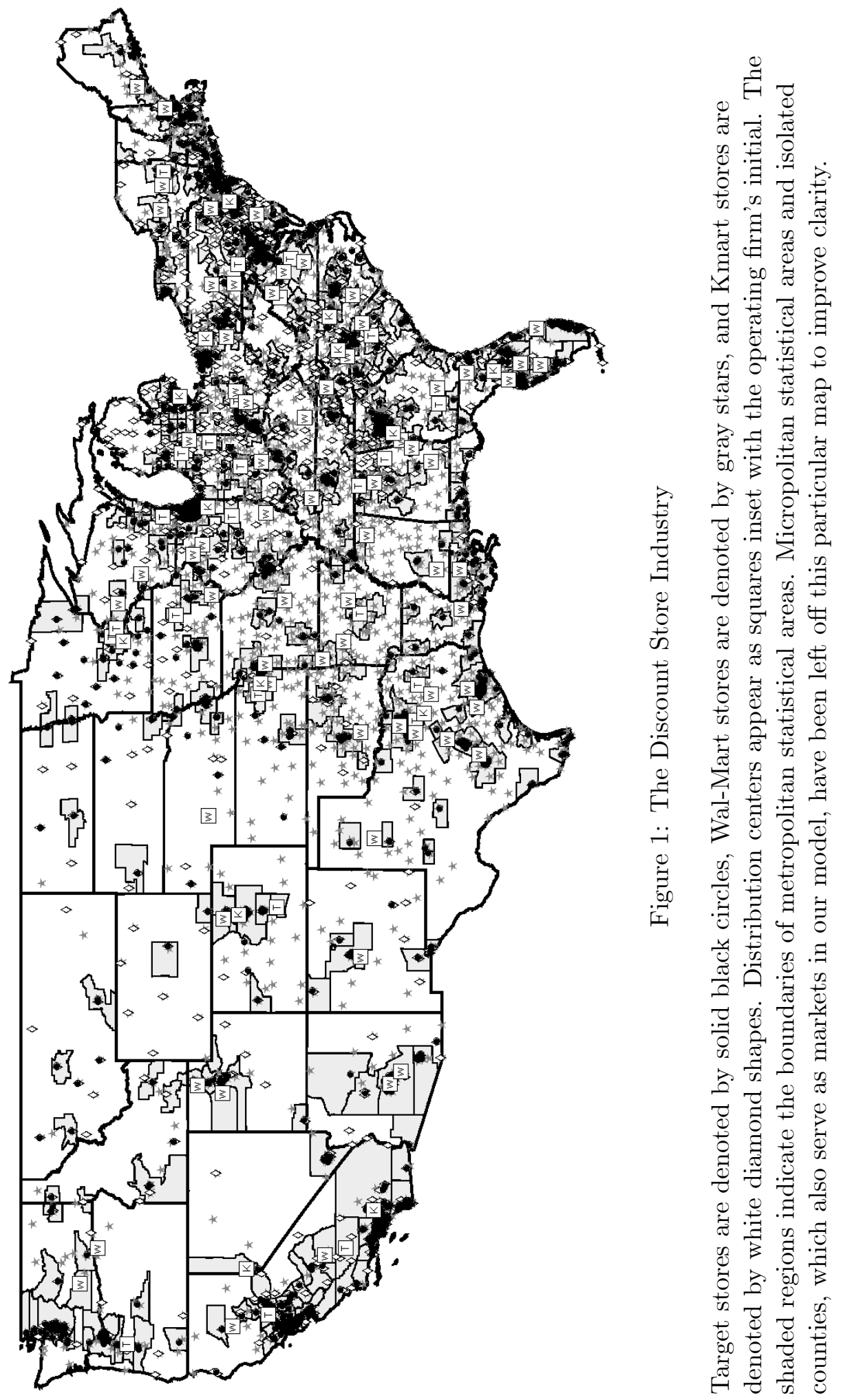


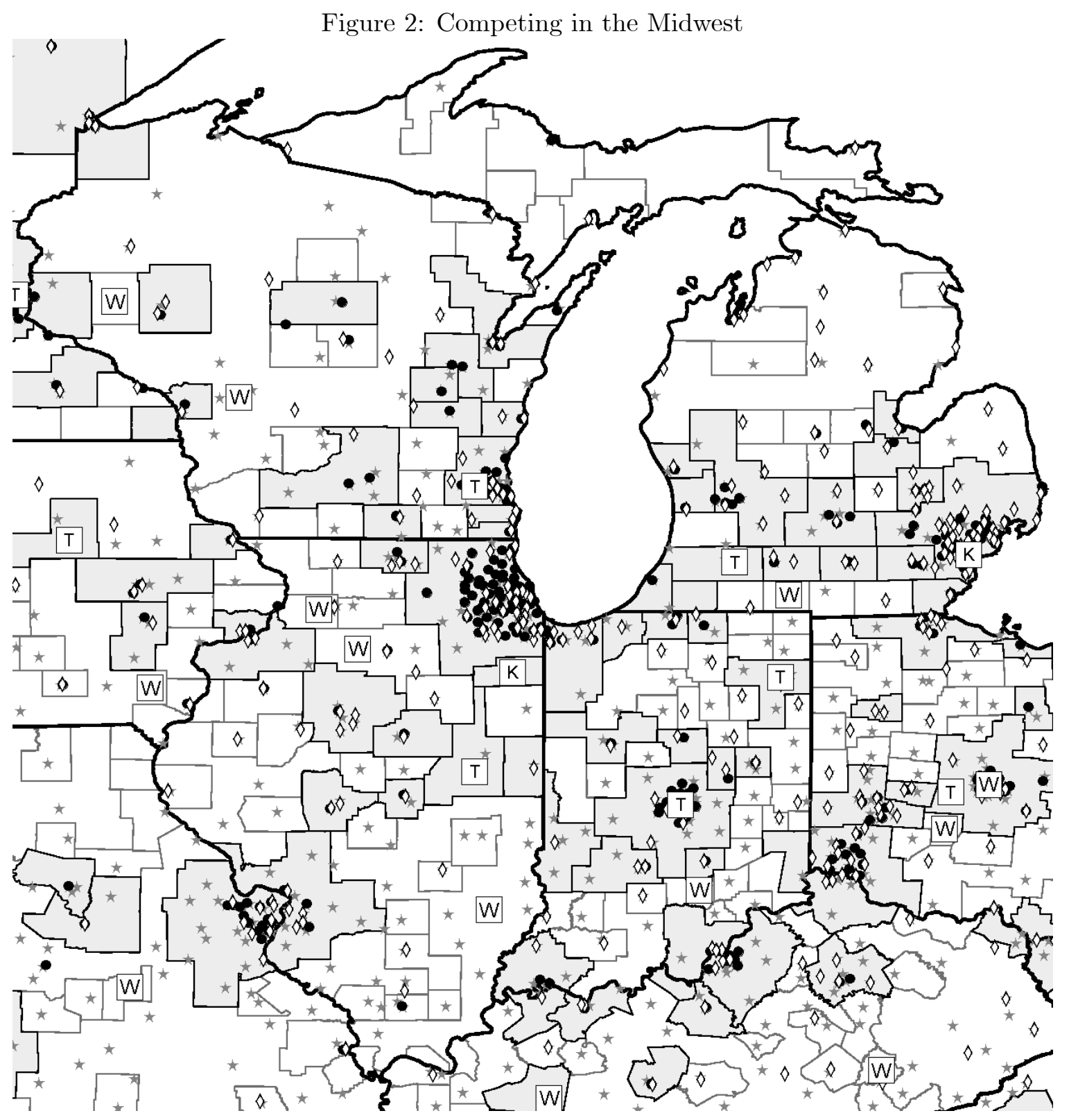

Target stores are denoted by solid black circles, Wal-Mart stores are denoted by gray stars, and Kmart stores are denoted by white diamond shapes. Distribution centers appear as squares inset with the operating firm's initial. The shaded regions indicate the boundaries of metropolitan statistical areas, while the unshaded regions indicate smaller micropolitan statistical areas. 
City), indicating that population is the primary driver of demand. The top right panel includes only those markets with population under 500,000, along with the fitted values from the median regression. Again, the relationship is linear, and fairly tightly clustered around the regression line at these low values of population. Following Bresnahan and Reiss (1990), we use order statistics from markets that contain only a single store to get a ballpark estimate of the minimum efficient scale (MES), in population units, that is required to support the first entrant. The median population $(26,450)$ and interquartile range $(18,420$; 38,240 ) for markets that contain just one store suggest that it takes about 25,000 people to induce the initial entry.

Nonetheless, there are several markets whose population is well below this critical level and yet contain one or more stores, and several more whose population is well above it yet contain just a single store (note that we are only plotting those markets that contain at least one store). Undoubtedly, the small markets with multiple outlets contain unobserved features (e.g. proximity to an interstate or highway interchange) that draw consumers from a larger geographic basin, while the larger markets with relatively few stores have offsetting unobservables (e.g. higher land prices and tighter zoning restrictions) that dampen entry. This heterogeneity, especially at the lowest levels of population, clearly illustrates why we need to control for market-level unobservables. There is often little in the data to explain why a market with 40,000 people has three discount stores but a market with 80,000 has just one. If we simply conditioned on the presence of own or rival stores, we would be biased toward finding a preference for agglomeration. This is exactly what we find below.

The bottom left panel returns to the full set of markets but switches the relationship from levels to logs, revealing a fairly tight, but heteroskedastic linear relationship (in logs). The fitted value line, which is from a restricted cubic spline regression, demonstrates a sharp kink near the level of $\ln$ (population) where we would expect to see a second store $(\ln (2 \times 25000) \approx 10.8)$, reflecting the inherent indivisibility of the big box format. A similar relationship holds firm by firm, as is demonstrated in the lower right panel, which contains fitted values from restricted cubic spline regressions for each firm. This obvious non-linearity further motivates our use of non-parametric fixed effects to control for features of the market which are common to all three firms. These empirical features will also motivate our choice of functional form in the following structural model of entry. 
Figure 3: Stores versus Population

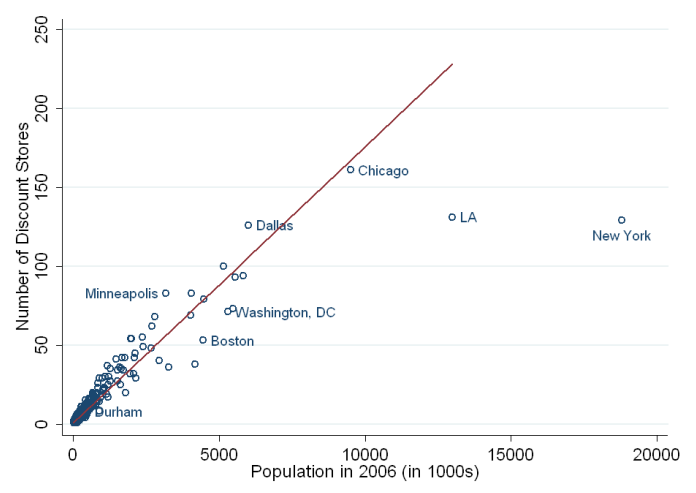

(a)

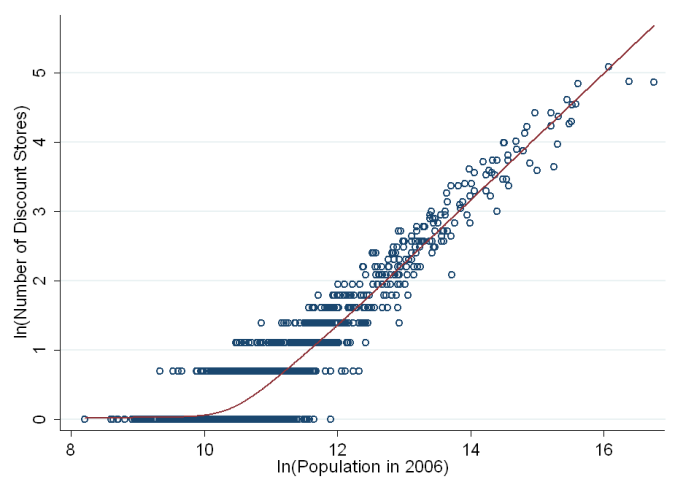

(c)

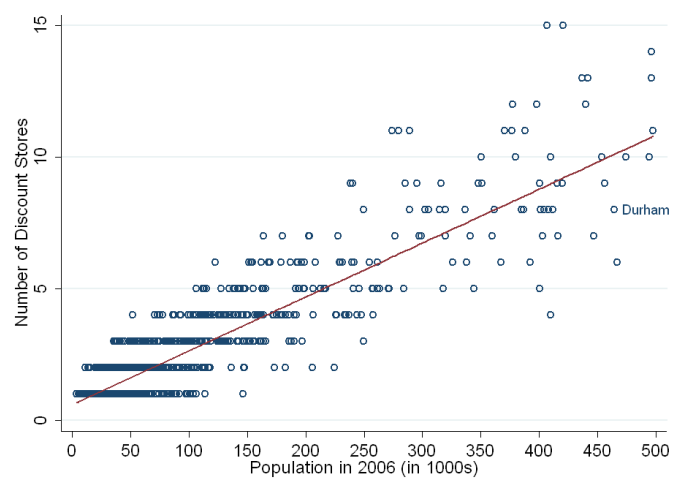

(b)

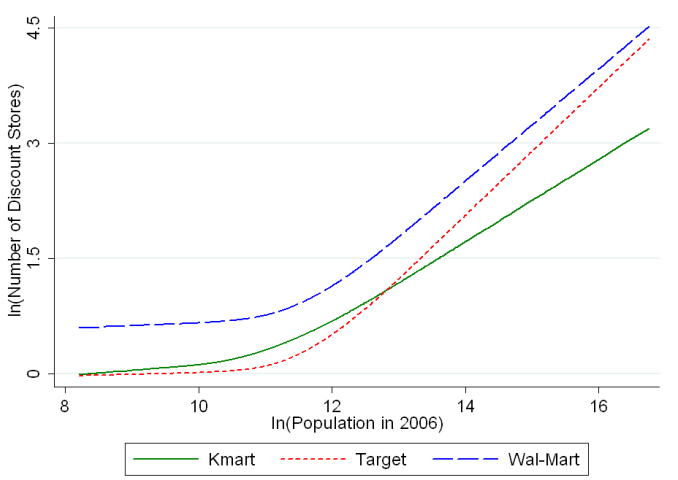

(d) 


\section{Model}

Since we do not have information on prices and quantities (or detailed store characteristics), we follow the standard convention of the entry literature in assuming that each firm's profit function is known up to a vector of parameters. We have chosen a functional form that is flexible in the number of own stores in order to accommodate net "chain" effects that may be either positive or negative. Consistent with the determinants of behavior described above, we begin by modeling the per-store payoff to firm $f=\{T, K, W\}$ of each store in market $j$ as:

$$
\begin{aligned}
\pi_{j}^{K}= & \beta^{K, \text { Own }} \ln \left(N_{j}^{K}+1\right)+\beta^{K, \text { Own } 2}\left(\ln \left(N_{j}^{K}+1\right)\right)^{2}+\beta^{K, \text { Own } 3}(\ln (\text { Pop }))\left(\ln \left(N_{j}^{K}+1\right)\right) \\
& +\beta^{K, \text { Other }} \ln \left(N_{j}^{W}+N_{j}^{T}+1\right)+\beta^{K, H Q} \ln \left(H Q_{j}^{K}\right)+\beta^{K, D C} \ln \left(D C_{j}^{K}\right)+\beta^{K, X} X_{j}+\theta_{j} \\
\pi_{j}^{T}= & \beta^{T, \text { Own }} \ln \left(N_{j}^{T}+1\right)+\beta^{T, \text { Own } 2}\left(\ln \left(N_{j}^{T}+1\right)\right)^{2}+\beta^{T, \text { Own } 3}(\ln (\text { Pop }))\left(\ln \left(N_{j}^{T}+1\right)\right) \\
& +\beta^{T, \text { Other }} \ln \left(N_{j}^{K}+N_{j}^{W}+1\right)+\beta^{T, H Q} \ln \left(H Q_{j}^{T}\right)+\beta^{T, D C} \ln \left(D C_{j}^{T}\right)+\beta^{T, X} X_{j}+\theta_{j} \\
\pi_{j}^{W}= & \beta^{W, \text { Own }} \ln \left(N_{j}^{W}+1\right)+\beta^{W, \text { Own } 2}\left(\ln \left(N_{j}^{W}+1\right)\right)^{2}+\beta^{W, \text { Own } 3}(\ln (\text { Pop }))\left(\ln \left(N_{j}^{W}+1\right)\right) \\
& +\beta^{W, \text { Other }} \ln \left(N_{j}^{T}+N_{j}^{K}+1\right)+\beta^{W, H Q} \ln \left(H Q_{j}^{W}\right)+\beta^{W, D C} \ln \left(D C_{j}^{W}\right)+\theta_{j}
\end{aligned}
$$

where $N_{j}^{f}$ is the total number of stores firm $f$ operates in market $j, D C_{j}^{f}$ is the distance from market $j$ to firm $f$ 's nearest distribution center, $H Q_{j}^{f}$ is the distance from market $j$ to firm $f$ 's headquarters, ${ }^{6} X_{j}$ is a vector of exogenous attributes of market $j$ (e.g., income, population, household size, regional dummies), $\beta$ is a vector of parameters $\left\{\beta^{f, \text { Own }}, \beta^{f, \text { Own } 2}, \beta^{f, \text { Own } 3}, \beta^{f, \text { Other }}, \beta^{f, H Q}, \beta^{f, D C}, \beta^{f, X}\right\}$ with $\beta^{W, X}=0$, and $\theta_{j}$ is a marketspecific fixed effect that is common to all firms. We further decompose this fixed effect as a combination of observable and unobservable market characteristics:

$$
\theta_{j}=f\left(X_{j} ; \gamma^{X}\right)+\xi_{j}
$$

where $\xi_{j}$ is an additively separable unobserved (to the econometrician) attribute of market $j$, that is assumed to be scalar, common across firms, and uncorrelated with $X_{j}$. Note that

\footnotetext{
${ }^{6}$ As Holmes (2008) demonstrates, Wal-Mart's outward expansion began from its headquarters in Bentonville, Arkansas. Target has had a historical presence near its parent-company (Dayton-Hudson) headquarters in Minneapolis, Minnesota. Kmart's ties to its original headquarters in Troy, Michigan are less apparent in it spatial layout.
} 
$f\left(X_{j} ; \gamma^{X}\right)$ captures the way in which the $X_{j}$ variables affect Wal-Mart's profits and is also important for determining how these variables impact the profits of the other two firms. In particular, if $f\left(X_{j} ; \gamma^{X}\right)$ were a simple linear function $\gamma^{X} X_{j}$, the impact of $X_{j}$ on Kmart's profits could be represented by $\left(\beta^{K, X}+\gamma^{X}\right) X_{j}$, while the effect of $X_{j}$ on Target's profits would follow from a comparable expression.

We expect to find $\beta^{f, D C}, \beta^{f, H Q}<0$, the former providing evidence that costly transportation creates incentives for firms to place stores closer to their distribution centers, and the latter documenting other coordination costs and the historical pattern of expansion from a firm's home base. The most important strategic parameters are $\beta^{f, O w n}, \beta^{f, O w n 2}, \beta^{f, O w n 3}$, and $\beta^{f, O t h e r}$, which capture the net impact of own and rival stores on firm profits. While the impact of rival stores should clearly be negative $\left(\beta^{f, \text { Other }}<0\right)$, the choice of functional form is designed to allow for flexibility in the effect of nearby own-stores on profits, leaving open the possibility of recovering either net agglomeration or business stealing effects over the range of store counts.

Since ex ante, per-store profits are the same at every store in a given market, calculating total firm-level profits involves summing over all $J$ markets: ${ }^{7}$

$$
\Pi^{f}=\sum_{j=1}^{J} N_{j}^{f} \times \pi_{j}^{f},
$$

This is, ultimately, the quantity that firms are maximizing through the choice of $N_{j}$ and the location of distribution centers (which in turn determines $D C_{j}^{f}$ in per-store profits). The derivative of $\pi_{j}^{f}$ with respect to $N_{j}^{f}$ reveals the presence of net agglomeration or ownbusiness stealing effects. In particular, over the range of $N_{j}^{f}$ where $\frac{d \pi_{j}^{f}}{d N_{j}^{f}}$ is positive, firm $f$ experiences net agglomeration effects in location $j$ (i.e., adding another store raises the marginal profitability of all stores in the location). Over the range where $\frac{d \pi_{j}^{f}}{d N_{j}^{f}}$ is negative, own-business stealing effects dominate agglomeration effects, and additional stores decrease the profitability of the firm's other stores in the market.

An important feature of our modeling framework is the inclusion of the unobserved market attribute, $\xi_{j}$, which serves as our structural error. From a practical standpoint,

\footnotetext{
${ }^{7}$ Note that our model only requires a firm's expectation of the profit at each store in a market to be the same at the time of siting. Profits will likely vary across stores after entry. We need only require that firms cannot predict these deviations.
} 
it is unlikely that our vector of observable market attributes, $X_{j}$, will capture everything about a market that is relevant to profitability. If we ignore these unobservable characteristics, we will likely arrive at biased estimates of a number of parameters - particularly those associated with $N_{j}^{f}$. Of course, explicitly including $\xi_{j}$ as part of the error structure creates potential endogeneity problems since $N_{j}^{f}$ is an equilibrium construct: $N_{j}^{f}$ is a direct function of $\xi_{j}$ as well as an indirect function of $\xi_{k} \forall k \neq j$. In solving this problem, we rely on three identification assumptions. First, the endogenous attributes of each market are firm-specific (i.e., the number of own-stores, stores operated by other firms, and distance to distribution center are different for each firm in each location). Second, the unobserved attribute $\xi_{j}$ is common across firms and additively separable in the profit function. Third, after controlling for the common unobservable $\xi_{j}$, any remaining errors are median independent of $N_{j}^{f}, N_{j}^{-f}$, and $D C_{j}^{f}$ when evaluated at the true parameter vector. The first two assumptions are common in both the sorting and discrete choice (demand) literature. The final assumption is closely related to the error decomposition described in Pakes et al. (2006). These disturbances could represent differences between the agent's ex ante expected profits and their realized values and/or measurement error in observable covariates or simple specification error. ${ }^{8}$ The essential requirement is that this error component is median independent of the information that the agent bases its decisions upon. In contrast to the alternative generalized discrete choice approach (Tamer (2003), Ciliberto and Tamer (2009)), it is difficult to give this error a structural interpretation as an additive component of the profit function; it is more naturally defined in differences (see below). However, it does eliminate the need to specify the content of agent's information sets or solve for equilibria conditional on all possible realizations of rival's choices (see Pakes (2008)), the latter of which is key for scalability.

It is crucial that we include key attributes of each market that might be valued differently by different firms. One obvious candidate is simply geography - the locations of corporate headquarters can explain much of Wal-Mart's prominence in the South and the ubiquitousness of Target in the upper Midwest. We model the equilibrium locations of all

\footnotetext{
${ }^{8}$ For example, we measure observable demographics like population and income using their 2006 values, but most of the entry decisions we model were taken over the previous 25 years. It seems reasonable to assume that firms may have incorrectly predicted how these variables would evolve over time.
} 
Targets, Wal-Marts, and Kmarts as of 2006. ${ }^{9}$ The locations of each firm's distribution centers are important determinants of these siting decisions, but are certainly not exogenously determined. There is a potentially complicated model of firms' decisions about where to place these distribution centers that we do not attempt to specify. Instead, we deal econometrically with the fact that $D C_{j}^{f}$ is endogenous, allowing us to recover unbiased estimates of firm preferences.

\subsection{Estimation of Strategic, Firm-Specific Parameters}

Our estimator is based on a revealed preference approach that uses pairwise comparisons between the observed location decisions made by firms and specific "single-store" deviations. The assumption is that a single-store deviation (i.e., taking a single store and moving it to a new location, holding the location decisions of other firms fixed) is a deviation from the observed Nash equilibrium strategy and is, therefore, payoff reducing for the firm.

Recall that the per-store profit of a given firm (say Target) in market $j$ is given by

$$
\begin{aligned}
\pi_{j}^{T}= & \beta^{T, \text { Own }} \ln \left(N_{j}^{T}+1\right)+\beta^{T, \text { Own } 2}\left(\ln \left(N_{j}^{T}+1\right)\right)^{2}+\beta^{T, \text { Own } 3}(\ln (\text { Pop }))\left(\ln \left(N_{j}^{T}+1\right)\right) \\
& +\beta^{T, \text { Other }} \ln \left(N_{j}^{K}+N_{j}^{W}+1\right)+\beta^{T, H Q} \ln \left(H Q_{j}^{T}\right)+\beta^{T, D C} \ln \left(D C_{j}^{T}\right)+\beta^{T, X} X_{j}+\theta_{j}
\end{aligned}
$$

Since the ex ante per-store profit is the same for every store in a given market, Target's total profit in market $j$ can be written

$$
\Pi_{j}^{T}=N_{j}^{T} \cdot\left(V_{j}^{T}\left(N_{j}^{T}\right)+\theta_{j}\right)
$$

where

$$
\begin{aligned}
V_{j}^{T}\left(N_{j}^{T}\right)= & \beta^{T, \text { Own }} \ln \left(N_{j}^{T}+1\right)+\beta^{T, \text { Own } 2}\left(\ln \left(N_{j}^{T}+1\right)\right)^{2}+\beta^{T, \text { Own } 3}(\ln (\text { Pop }))\left(\ln \left(N_{j}^{T}+1\right)\right) \\
& +\beta^{T, \text { Other }} \ln \left(N_{j}^{K}+N_{j}^{W}+1\right)+\beta^{T, H Q} \ln \left(H Q_{j}^{T}\right)+\beta^{T, D C} \ln \left(D C_{j}^{T}\right)+\beta^{T, X} X_{j}
\end{aligned}
$$

Note that $N_{j}^{W}$ and $N_{j}^{K}$ are implicitly held at their observed values in $V_{j}^{T}\left(N_{j}^{T}\right)$, as we only consider unilateral deviations. The logic of the estimator is to consider "swaps" of a single store from one market to another. For example, consider moving a single Target store from market a (e.g., Minneapolis), which currently contains $N_{a}^{T}$ Target stores,

\footnotetext{
${ }^{9}$ Following the standard practice in the static entry literature, we treat the entire network of each firm as being determined simultaneously in a one-shot game. In contrast, Holmes (2008) models the dynamics of store diffusions, albeit from the perspective of only a single firm.
} 
to market $b$ (e.g., Chicago), which currently contains $N_{b}^{T}$ Target stores. Since the observed configuration $\left(N_{a}^{T}, N_{b}^{T}\right)$ is part of an equilibrium, Target's total profits must be higher under the observed configuration than under the proposed counterfactual configuration $\left(N_{a}^{T}-1, N_{b}^{T}+1\right)$. Note that since all "spillovers" (i.e., congestion effects or economies of density) are assumed to occur within, but not across, CBSA markets (i.e., profits are additively separable across markets) the change in total firm profits only depends on the incremental changes associated with the two markets exchanging stores, yielding the following relatively simple profit inequality

$$
\begin{aligned}
& N_{a}^{T} \cdot V_{a}^{T}\left(N_{a}^{T}\right)+N_{a}^{T} \cdot \theta_{a}+N_{b}^{T} \cdot V_{b}^{T}\left(N_{b}^{T}\right)+N_{b}^{T} \cdot \theta_{b} \\
& \quad \geq\left(N_{a}^{T}-1\right) \cdot V_{a}^{T}\left(N_{a}^{T}-1\right)+\left(N_{a}^{T}-1\right) \cdot \theta_{a}+\left(N_{b}^{T}+1\right) \cdot V_{b}^{T}\left(N_{b}^{T}+1\right)+\left(N_{b}^{T}+1\right) \cdot \theta_{b}
\end{aligned}
$$

Simplifying this expression yields

$$
\widetilde{\Delta V}_{a}^{T}\left(N_{a}^{T}, N_{a}^{T}-1\right)+\widetilde{\Delta V}_{b}^{T}\left(N_{b}^{T}, N_{b}^{T}+1\right)+\left(\theta_{a}-\theta_{b}\right) \geq 0
$$

where the $\widetilde{\Delta V}_{j}^{f}(\cdot, \cdot)$ notation represents the decrease (or increase) in profits associated with removing a single store from (or adding a single store to) a particular market.

An impediment to using this simple inequality to recover the structural parameters of Target's payoff function is the difference in fixed effects, $\left(\theta_{a}-\theta_{b}\right)$, which, if treated as the econometric error, would clearly be correlated with the included regressors. In addition to the valuation of the exogenous features of the market which are common to all players (represented here as Wal-Mart's preferences over population, for example), these fixed effects capture the parameters $\xi_{a}$ and $\xi_{b}$, which are common knowledge of the firms, but unobserved by the econometrician. To obtain unbiased estimates of the profit parameters, we must eliminate these common unobservables from the profit inequality. Therefore, we consider another hypothetical store movement that will allow us to difference these fixed effects away. In particular, consider moving one Kmart store from $b$ to $a$. This yields an inequality similar to the one above, but with an offsetting difference in the fixed effect term:

$$
\widetilde{\Delta V}_{a}^{K}\left(N_{a}^{K}, N_{a}^{K}+1\right)+\widetilde{\Delta V}_{b}^{K}\left(N_{b}^{K}, N_{b}^{K}-1\right)+\left(\theta_{b}-\theta_{a}\right) \geq 0
$$

Adding Equation (2) to Equation (1) yields another inequality that is free from this prob- 
lematic term: ${ }^{10}$

$$
\begin{aligned}
\widetilde{\Delta V}_{a}^{T}\left(N_{a}^{T}, N_{a}^{T}-1\right)+\widetilde{\Delta V}_{b}^{T}\left(N_{b}^{T}\right. & \left., N_{b}^{T}+1\right) \\
& +\widetilde{\Delta V}{ }_{a}^{K}\left(N_{a}^{K}, N_{a}^{K}+1\right)+\widetilde{\Delta V}_{b}^{K}\left(N_{b}^{K}, N_{b}^{K}-1\right) \geq 0
\end{aligned}
$$

Using the same logic, we construct many "offsetting" swaps of stores between the three retailers. ${ }^{11}$ By considering many such "minor perturbations" to the observed spatial network of stores, we are able to construct a pairwise maximum score objective function with which to estimate the $\beta$ parameters. (The remaining (common) parameters, $\gamma^{X}$, are estimated in a second step.) Because we have explicitly controlled for the structural error in $\xi_{j}$, we now assume that any remaining idiosyncratic error in Inequality (3) is i.i.d. across stores, firms, and markets. Continuing with the example of our Target-Kmart swap:

$$
\begin{aligned}
& \widetilde{\Delta V}_{a}^{T}\left(N_{a}^{T}, N_{a}^{T}-1\right)+\widetilde{\Delta V}_{b}^{T}\left(N_{b}^{T}, N_{b}^{T}+1\right) \\
& \quad+\widetilde{\Delta V}_{a}^{K}\left(N_{a}^{K}, N_{a}^{K}+1\right)+\widetilde{\Delta V}_{b}^{K}\left(N_{b}^{K}, N_{b}^{K}-1\right) \geq\left(\varepsilon_{a}^{T}-\varepsilon_{b}^{T}\right)+\left(\varepsilon_{b}^{K}-\varepsilon_{a}^{K}\right)=v_{a b}^{T K}
\end{aligned}
$$

This error explains why the inequality will not necessarily hold for every store swap that we consider. As noted above, it represents either specification or measurement error in the latent profit function that is median independent of the conditioning variables. ${ }^{12}$ Under

\footnotetext{
${ }^{10}$ It would also have been possible to apply this differencing procedure to inequalities involving a single location, rather than pairs of locations. For example, instead of creating an alternative configuration with one less Target store in location $a$ and one more Target store in location $b$, we might have considered an alternative with simply one less Target store in location $a$. This alternative would also be profit-reducing. Then, an offsetting inequality could be generated by adding one Kmart store to location $a$ (also profitreducing for Kmart). When combining the inequalities, the common $\theta_{a}$ would drop out. The current approach of double-differencing has the (small) advantage of holding the total number of stores fixed. This is important in that we do not attempt to model (nor does our approach require) the firm's decision about how many stores to build in total.

${ }^{11}$ In particular, we randomly select 15,000 pairs of locations (with replacement) from the full set of existing stores. This effectively weights the draws by population, since more populated areas will have more stores. In addition, because there are twice as many Wal-Mart stores as Kmart or Target stores, a higher percentage of the inequalities will involve Wal-Mart-Kmart or Wal-Mart-Target pairings, than will involve Target-Kmart pairings. The choice of 15,000 itself is somewhat arbitrary; similar results were obtained using fewer and using more random pairs.

${ }^{12}$ In the notation of Pakes (2008), $v_{1, i}$ plays a role analogous to $v_{a b}^{f_{1} f_{2}}$. Pakes describes this error as being composed of two terms. The first represents "the difference between the agent's expectation of profits at the time the agent makes its decision and the realization of profits. It is a result of uncertainty in the exogenous variables that will eventually help determine profits." He describes the second component as "that part of the error in our measure of profits that is mean independent of the information the agent bases its decision on. It will be generated by specification error in our profit functions and/or measurement error in
} 
this assumption, the rank-ordering property defined by Manski (1975) and further described by Fox (2007) is preserved, and consistent estimates of the parameters can be obtained using only this subset of the almost uncountable number of alternative configurations. Manski (1985) established that point identification of the $\beta$ parameters requires at least one regressor with absolutely continuous support on the real line. This regressor is needed to "break ties" between candidate $\beta$ 's, winnowing the identified set to a point. Distances to the nearest distribution center and the firm's headquarters, which will always vary across locations and players, are natural candidates for such a regressor since we only consider switching stores from one market to another. In the absence of this special regressor, maximum score could still be used to trace out the identified set, but a different inference procedure would be required to construct confidence sets.

In practice, the non-smoothness of the maximum score objective function makes optimization difficult, so we use smoothed maximum score with a normal kernel, and bootstrap with sub-sampling to obtain standard errors. ${ }^{13}$ We also note that when estimating with these inequalities in a maximum score or smoothed maximum score framework, we must normalize one of the coefficients; for the results presented in Section 4, the coefficient on Wal-Mart's distance to its headquarters in Bentonville, Arkansas is normalized to -1. All of the other parameter estimates are therefore expressed in this metric.

Finally, it is important to note what has happened with the endogenously determined local attributes $\left(N_{j}^{f, \text { Own }}, N_{j}^{f, \text { Other }}, D C_{j}^{f}\right)$ in this system. We would expect each of these to be correlated with $\xi_{j}$. That is, places that are desirable owing to unobserved factors are likely to have more stores in them, both Own and Other). Locations surrounded by locations with desirable unobservables are, similarly, more likely to be close to a distribution center (assuming distribution centers are placed with the goal of serving a large number of attractive markets). The key to our estimation strategy is that $\xi_{j}$ no longer appears in our objective function when it comes time to estimate the parameter vector $\beta$. However, the other elements of $\theta_{j}$ (apart from $\xi_{j}$ ), which are clearly critical to giving a meaningful

the variables used to construct profits." One possible reason to expect such an unobservable to be present in our model is that the observable, exogenous determinants of profits in 2006 may be very different (in an unpredictable way) from what the firm expected when it originally sited its stores. It could also reflect asymmetric information regarding the unobserved "types" of one's rivals.

${ }^{13}$ We use a simulated annealing algorithm to search for the global optimum. Formal proofs of consistency are provided in Fox (2007) and Bajari and Fox (2009), which build on the arguments laid out in Han (1987). 
economic interpretation to several of the parameters recovered in the first stage, have also been differenced away. This is an issue in any procedure that involves differencing out common unobservables. An important contribution of our framework is a method for recovering these additional parameters in a second stage. We turn to this exercise next.

\subsection{Decomposing the Market-Level Fixed Effects}

Crucial to our understanding of firm entry behavior is the recovery of the parameters $\gamma^{X}$, which are included in $\theta_{j}$, the fixed effect terms that were differenced out of Equation (3). Recall from above that these parameters describe how the demographic variables included in $X_{j}$ affect Wal-Mart's profits. The impact of $X_{j}$ on Kmart's and Target's profits are represented by $f\left(X_{j} ; \gamma^{X}\right)+X_{j}^{\prime} \beta^{K, X}$ and $f\left(X_{j} ; \gamma^{X}\right)+X_{j}^{\prime} \beta^{T, X}$, respectively. Although we have already obtained estimates of $\beta^{K, X}$ and $\beta^{T, X}$ in the first stage, we clearly need to know Wal-Mart's values (captured only by $f\left(X_{j} ; \gamma^{X}\right)$ ) in order to determine the overall value that any firm places on an attribute like per-capita income or population. Because we were concerned that $\xi_{j}$ would be correlated with all the $N$ 's, we included it in the fixed effect $\left(\theta_{j}\right)$ and differenced it out in the first stage. A key advantage of our two-stage approach is that estimates of the first-stage parameters can be recovered without having to specify a particular functional form for $f\left(X_{j} ; \gamma^{X}\right)$. However, if we want to learn the baseline effects of $X_{j}$ on all firms' profitabilities, we need to commit to a particular functional form; here, we use $X_{j}^{\prime} \gamma^{X}$. We can then use our first stage estimates, along with an assumption on firm behavior, to recover (set valued) estimates of the fixed effects. We can then project these interval estimates onto $X$ using Beresteanu and Molinari's (2008) techniques for set valued random variables.

We begin this process by recovering estimates for the market-specific fixed effects. With only three firms and without making explicit distributional assumptions, we are unable to recover point estimates of each $\theta_{j}$. There is simply not enough information in data describing the store siting decisions of just three firms to identify the precise values of this many parameters. However, we can recover ranges in which those parameters must lie and use these intervals to set-identify $\gamma^{X}$. In order to do so, we make use of an additional assumption about firm behavior similar to that employed by Pakes et al. (2006). In 
particular, we begin with each firm's marginal profitability of stores in each market $j$ :

$$
\begin{array}{ll}
\frac{\partial \Pi^{T}}{\partial N_{j}^{T}} & =\frac{N_{j}^{T}}{N_{j}^{T+1}}\left[\beta^{T, \text { Own }}+2 \beta^{T, \text { Own } 2} \ln \left(N_{j}^{T}+1\right)+\beta^{T, \text { Own } 3} \ln (\text { Pop })\right]+\pi_{j}^{T} \\
\frac{\partial \Pi^{K}}{\partial N_{j}^{K}} & =\frac{N_{j}^{K}}{N_{j}^{K}+1}\left[\beta^{K, \text { Own }}+2 \beta^{K, \text { Own } 2} \ln \left(N_{j}^{K}+1\right)+\beta^{K, \text { Own } 3} \ln (\text { Pop })\right]+\pi_{j}^{K} \\
\frac{\partial \Pi^{W}}{\partial N_{j}^{W}} & =\frac{N_{j}^{W}}{N_{j}^{W}+1}\left[\beta^{W, \text { Own }}+2 \beta^{W, \text { Own } 2} \ln \left(N_{j}^{W}+1\right)+\beta^{W, \text { Own } 3} \ln (\text { Pop })\right]+\pi_{j}^{W}
\end{array}
$$

Note that we will not attempt to recover the determinants of the total number of stores that each firm builds. This will be affected by capital constraints and cash reserves, longrun business plans, access to foreign suppliers, and so forth. Instead, we assume only that each firm allocated whatever stores it did build in an optimal fashion - that is, they added stores to each market until the marginal profitability of the last store added was equalized across markets, up to an integer constraint. In particular, for each firm $f$, there is a constant value $c^{f}$ such that observed marginal profits in each market with at least one store must be greater than $c^{f}$, while the marginal profits from one additional store must be less than $c^{f}$ :

$$
\begin{array}{r}
\frac{N_{j}^{f}}{N_{j}^{f}+1}\left[\beta^{T, \text { Own }}+2 \beta^{T, \text { Own } 2} \ln \left(N_{j}^{T}+1\right)\right. \\
\left.+\beta^{T, \text { Own } 3} \ln (\text { Pop })\right] \\
+V_{j}^{T}\left(N_{j}^{T}\right)+\theta_{j} \geq c^{f} \\
\frac{N_{j}^{f}+1}{N_{j}^{f}+2}\left[\beta^{T, \text { Own }}+2 \beta^{T, \text { Own } 2} \ln \left(N_{j}^{T}+2\right)+\beta^{T, \text { Own } 3} \ln (\text { Pop })\right] \\
+V_{j}^{T}\left(N_{j}^{T}+1\right)+\theta_{j}<c^{f}
\end{array}
$$

where $\beta^{f, X}=0$ if $f=W$. Note that in markets where the firm has zero stores, it is at a corner solution and only Equation (6) must hold. We define the following components of firm $f$ 's marginal profits in market $j$ :

$$
\begin{aligned}
\psi_{1, j}^{f} & \equiv \frac{N_{j}^{f}}{N_{j}^{f}+1}\left[\beta^{T, \text { Own }}+2 \beta^{T, \text { Own } 2} \ln \left(N_{j}^{T}+1\right)+\beta^{T, \text { Own } 3} \ln (\text { Pop })\right]+V_{j}^{T}\left(N_{j}^{T}\right) \\
\psi_{2, j}^{f} & \equiv \frac{N_{j}^{f}+1}{N_{j}^{f}+2}\left[\beta^{T, \text { Own }}+2 \beta^{T, \text { Own } 2} \ln \left(N_{j}^{T}+2\right)+\beta^{T, \text { Own } 3} \ln (\text { Pop })\right]+V_{j}^{T}\left(N_{j}^{T}+1\right)
\end{aligned}
$$

Since we have estimated all the $\beta$ parameters in the first stage (and observe everything else), we can treat this component of marginal profits as known. ${ }^{14}$ Because payoffs are only

\footnotetext{
${ }^{14} \mathrm{We}$ will correct for the fact that these are estimates in the second stage standard errors.
} 
identified up to an additive scale parameter in any discrete choice framework, we have one free normalization. Setting the value of $\theta_{j}$ equal to zero for some base location, we have: ${ }^{15}$

$$
\psi_{2, \text { base }}^{f}<c^{f} \leq \psi_{1, \text { base }}^{f}
$$

With these bounds on $c^{f}$ for each firm, we can now use Equations (5) and (6) to bound $\theta_{j}$ for each firm:

$$
\begin{aligned}
& \psi_{2, \text { base }}^{f}-\psi_{1, j}^{f}<\theta_{j}<\psi_{1, \text { base }}^{f}-\psi_{2, j}^{f}, \quad \text { if } N_{j}^{f}>0 \\
& \theta_{j}<\psi_{1, \text { base }}^{f}-\psi_{2, j}^{f}, \quad \text { if } N_{j}^{f}=0
\end{aligned}
$$

Assuming that the $\theta_{j}$ 's are the same for all firms, the intersection of these bounds describes the set of admissible values that $\theta_{j}$ can take for each market $j .{ }^{16}$ Note that if we had point estimates of the $\theta_{j}$ 's, we could simply project them onto $X$ using a linear regression. However, because the $\theta_{j}$ 's are set identified, our dependent variable now comes in interval form: $\theta_{j} \in\left[\theta_{L j}, \theta_{U j}\right]$. Therefore, we rely on the methods developed by Beresteanu and Molinari (2008), which use a transformed Minkowski average of the data to recover bounds and confidence sets for $\gamma^{X}$. This is described in detail in Appendix B.

\section{Results}

Our main empirical results are presented in Tables 1 and 3 for several alternative specifications of the model. Table 1 reports the parameter estimates for the firm-specific components of per-store profits, which were recovered in the first stage of our two-step procedure. The results from the second stage are presented in Table 3. Column I of Table 1 contains the results from our main (preferred) specification, which we discuss in detail below. Column II reports results from a specification that does not include location-specific unobservables ( $\xi$ 's), while Column III is a specification that only includes stores sited after 2000 (as a robustness check).

\footnotetext{
${ }^{15}$ In practice, the base location used is the Albany, Georgia Metropolitan Area. Kmart, Target, and WalMart each have one store there. The area's population is around the 75th percentile and the population density is close to the median value of all metro and micropolitan areas in our sample.

${ }^{16}$ Note that we drop from the $\theta_{j}$ decomposition exercise seven locations where the sets of $\theta_{j}$ 's are disjoint (i.e., where no value of $\theta_{j}$ can satisfy all three firms inequalities). This is an indication of model misspecification. Because this only happens with a small fraction of our overall locations, we ignore any possible resulting sample selection in the decomposition of $\theta_{j}$.
} 
Focusing on the main results from the first stage (Column I of Table 1), several features are worth noting. Since this is a highly non-linear specification, we begin with a simple discussion of signs and significance and then present marginal effects for the main variables of interest. The signs of all coefficients are as expected and most are significant at the usual levels. In particular, we find that rival stores have a negative and significant impact on own profitability that is strongest for Kmart and weakest for Wal-Mart. This implies that WalMart (and to a lesser extent, Target) is better able to keep customers in the face of entry by a rival firm in the same market; Kmart tends to lose more customers to that new entrant. This is consistent with aspects of the differing business models adopted by each company. Wal-Mart emphasizes "every day low prices" and chooses locations in which customers are willing to drive long distances to get those low prices. Target markets an upscale product, typically choosing higher income, urban locations in which to do so. It makes sense that either firm would be well-positioned to fend off entry by the other (or by Kmart) and maintain its customer base. Kmart, on the other hand, has adopted a mixed strategy of low prices (epitomized by their (in)famous "blue light" specials) and celebrity brand names (e.g. Martha Stewart and Kathy Ireland), making their product more substitutable with both Wal-Mart and Target, depending on the location they are in. Looking at the remaining parameters, distance to headquarters is negative, but significant only for Kmart, while distance to the closest distribution center is negative, but insignificant. The effect of own stores involves three coefficients, requiring an analysis of marginal effects. As we will see below, their net effect is negative, implying that business stealing outweighs local density economies at the margin.

An attractive feature of our model is that it allows firms to profit differently from observable characteristics of the market. This firm-level heterogeneity is apparent in the coefficient estimates. Target, which is located primarily in metropolitan areas, has the strongest preference for higher population relative to both Kmart and Wal-Mart, while Wal-Mart has the weakest. This is consistent with conventional wisdom regarding each firm's preferred demographic. ${ }^{17}$

Finally, the smoothed maximum score as a fraction of the total number of comparisons

\footnotetext{
${ }^{17}$ Other specifications not reported here include measures of population density, median income, and average household size. The results for the competitive and own-firm effects showed a similar pattern, but the coefficients on the demographic characteristics were insignificant.
} 
can be used as a measure of fit. The value here is $97 \%$, indicating a very tight fit (note the sharp contrast with the specification in Column II that does not include the marketlevel unobservable $\xi$ ). This implies that the store-specific idiosyncratic errors $\left(\varepsilon_{j}^{f}\right.$ 's) play a relatively minor role in explaining observed choices. This likely reflects the fact that population alone captures most of the relevant differences in demand across markets, while the common unobservables (the $\xi_{j}$ 's) account for the bulk of the rest.

Table 1: First Stage Estimates

\begin{tabular}{|c|c|c|c|c|c|c|}
\hline & \multicolumn{2}{|c|}{ I } & \multicolumn{2}{|c|}{ II } & \multicolumn{2}{|c|}{ III } \\
\hline & $\beta$ & S.E. & $\beta$ & S.E. & $\beta$ & S.E. \\
\hline \multicolumn{7}{|l|}{ Kmart-Specific Covariates } \\
\hline $\ln \left(N_{\text {own }}+1\right)$ & -225.738 & 10.54 & -57.120 & 15.66 & \multirow[t]{6}{*}{$\S$} & \\
\hline$\left(\ln \left(N_{\text {own }}+1\right)\right)^{2}$ & -10.439 & 0.68 & -1.887 & 0.94 & & \\
\hline $\ln (P o p)\left(\ln \left(N_{\text {own }}+1\right)\right)$ & 17.291 & 0.85 & 4.139 & 1.17 & & \\
\hline $\ln \left(N_{\text {other }}+1\right)$ & -121.331 & 7.81 & -59.124 & 15.92 & & \\
\hline $\ln ($ Distance to $\mathrm{HQ})$ & -1.779 & 0.43 & -11.277 & 4.96 & & \\
\hline $\ln$ (Population) & 9.987 & 3.75 & 18.576 & 7.06 & & \\
\hline \multicolumn{7}{|l|}{ Target-Specific Covariates } \\
\hline $\ln \left(N_{\text {own }}+1\right)$ & -201.378 & 5.03 & -24.189 & 13.77 & -207.799 & 7.35 \\
\hline$\left(\ln \left(N_{\text {own }}+1\right)\right)^{2}$ & -8.290 & 0.46 & 3.650 & 1.42 & -11.456 & 0.65 \\
\hline $\ln (P o p)\left(\ln \left(N_{\text {own }}+1\right)\right)$ & 14.361 & 0.50 & -1.052 & 0.83 & 13.572 & 0.68 \\
\hline $\ln \left(N_{\text {other }}+1\right)$ & -105.965 & 6.64 & -24.118 & 9.23 & -184.839 & 12.94 \\
\hline $\ln ($ Distance to $\mathrm{HQ})$ & -0.094 & 0.28 & -8.994 & 3.59 & -9.553 & 0.49 \\
\hline $\ln$ (Population) & 13.056 & 2.83 & 20.523 & 15.00 & 29.530 & 5.27 \\
\hline \multicolumn{7}{|l|}{ Wal-Mart-Specific Covariates } \\
\hline $\ln \left(N_{o w n}+1\right)$ & -223.268 & 8.06 & 16.529 & 5.27 & -224.161 & 10.32 \\
\hline$\left(\ln \left(N_{\text {own }}+1\right)\right)^{2}$ & -10.887 & 1.18 & 6.203 & 1.94 & -17.666 & 1.02 \\
\hline $\ln ($ Pop $)\left(\ln \left(N_{\text {own }}+1\right)\right)$ & 16.045 & 0.70 & -4.252 & 1.28 & 15.957 & 0.70 \\
\hline $\ln \left(N_{\text {other }}+1\right)$ & -85.222 & 5.95 & -11.613 & 3.80 & -131.678 & 9.71 \\
\hline $\ln ($ Distance to $\mathrm{HQ})$ & $-1 \dagger$ & & $-1 \dagger$ & & $-1 \dagger$ & \\
\hline \multicolumn{7}{|l|}{ Common Covariates } \\
\hline $\ln ($ Distance to DC) & -0.265 & 0.30 & -0.935 & 0.36 & 1.347 & 0.55 \\
\hline $\ln ($ Pop $)$ up to $\ln (50,000)$ & $\ddagger$ & & 3.178 & 1.82 & $\ddagger$ & \\
\hline $\ln ($ Pop $)$ over $\ln (50,000)$ & $\ddagger$ & & 23.675 & 6.95 & $\ddagger$ & \\
\hline Number of Comparisons & \multirow{2}{*}{\multicolumn{2}{|c|}{$\begin{array}{c}15000 \\
14518.88\end{array}$}} & \multirow{2}{*}{\multicolumn{2}{|c|}{$\begin{array}{c}30000 \\
2210580\end{array}$}} & \multirow{2}{*}{\multicolumn{2}{|c|}{$\begin{array}{c}15000 \\
14327.72\end{array}$}} \\
\hline Smoothed Maximum Score & & & & & & \\
\hline
\end{tabular}

$\dagger$ Maximum score estimation requires the normalization of one parameter. In all models shown here, the Wal-Mart-specific coefficient on distance to headquarters is normalized to -1 . The standard errors for the remaining estimated coefficients are reported in italics.

$\ddagger$ These common components of the profit function are differenced out as part of the location fixed effect. They are estimated in a separate second stage, the results of which are reported in Table 3. In Specification II, because we have dropped the unobservable location-specific characteristic, there is no need to use the differencing approach; all parameters can be recovered in a single stage.

$\S$ Specification III estimates the model using only stores placed since 2000 to construct inequalities. Since Kmart did not open any new stores between 2000 and 2006, we do not estimate coefficients for this firm.

To further unpack the nature of network competition, Table 2 presents the marginal effects of own and rival stores on per-store profit. These first derivatives are evaluated at 
Table 2: Comparing Marginal Effects of Own and Rival Stores on Per-Store Profit

\begin{tabular}{|c|cccccc|}
\hline Evaluated at & \multicolumn{2}{|c}{ Kmart } & \multicolumn{2}{c|}{ Target } & \multicolumn{2}{c|}{ Wal-Mart } \\
& Own & Rival & Own & Rival & Own & Rival \\
\hline $\begin{array}{c}1 \text { own store, 1 rival store } \\
\text { (population=46,610) }\end{array}$ & -27.2 & -60.7 & -29.2 & -53.0 & -32.9 & -42.6 \\
2 own stores, 2 rival stores \\
$\quad$ (population=137,991) \\
5 own stores, 5 rival stores \\
$\quad$ (population=431,904) \\
$10 \begin{array}{c}\text { own stores, 10 rival stores } \\
\text { (population=816,811) }\end{array}$ & -14.7 & -40.4 & -16.5 & -35.3 & -19.1 & -28.4 \\
\hline
\end{tabular}

The population values used to evaluate these marginal effects are the median populations for markets with the given number of total stores.

several values of own and rival stores and at the median level of population for markets with the chosen number of stores. As noted above, we find that Wal-Mart is hurt the least by increased competition from rivals, reflecting either its well-planned marketing strategy or simply its widely-perceived global cost advantages and better overall brand awareness. However, Kmart and Target suffer less than Wal-Mart from the introduction of additional own stores. ${ }^{18}$ Moreover, the local chain effect, captured by the wedge between the "own" and "other" effects, is strongest for Kmart and weakest for Wal-Mart. This implies that Kmart and Target enjoy a comparative advantage in local density economies, particularly in areas with high population. This is consistent with well-documented differences in the firms' business models: Kmart and Target rely more on local price promotion and advertising than Wal-Mart, a strategy more suited to urban (or high density) markets where costs can be spread across multiple outlets and consumers can visit stores more frequently (to take advantage of deals). Wal-Mart's more diffuse layout complements its "every day low price" positioning, which requires less promotion and allows customers to make fewer trips to the store. Kmart also tailors its products more closely to local tastes, explicitly courting Hispanic and African American customers in areas in which these demographic groups are

\footnotetext{
${ }^{18}$ The marginal effects are all monotonically decreasing in population, which simply reflects the fact that adding a single store to a market with 50,000 consumers has a much larger impact on per store profits than adding that same store to a market of five million.
} 
well-represented. Overall, these results suggest that Wal-Mart's comparative advantage is more global, perhaps tied to the well-known logistical advantages and buying power with suppliers, while Kmart and Target benefit more from local economies of density. After decomposing the market-level fixed effects and discussing robustness, we will return to this point with a detailed counterfactual.

Table 3: Second Stage Estimates

\begin{tabular}{|l|c|c|}
\hline \hline & $\mathrm{I}(\mathrm{a})$ & $\mathrm{I}(\mathrm{b})$ \\
\hline $\ln$ (Population) & $(28.35,64.95)$ & $(15.57,70.29)$ \\
$\ln$ (Median Income) & {$[14.71,78.58]$} & {$[1.12,84.74]$} \\
& & $(-182.41,154.84)$ \\
Avg. Household Size & & $(-208.47,180.9]$ \\
& & $(-163.61,87.48)$ \\
$\%$ Urban & & $(-184.4,108.27]$ \\
& & {$[-134.45,240.11]$} \\
Constant & & $(-1000.83,282.45)$ \\
& $(-735.41,-299.78)$ & {$[-1190.96,472.58]$} \\
\hline Number of Observations & {$[-892.25,-142.94]$} & 1344 \\
\hline
\end{tabular}

Specifications $I(a)$ and $I(b)$ use the first-stage estimates from specification I in Table 1 . The intervals appearing in square brackets represent the largest $95 \%$ confidence collection, i.e., the largest set that, when specified as a null hypothesis for the true value of the population identification region, cannot be rejected by a $95 \%$ test.

The results from the second stage are reported in Table 3. The bounds and $95 \%$ confidence sets for the coefficient for log population are positive in all our specifications, indicating, as expected, that larger markets are more profitable. ${ }^{19}$ We also note that, while the first-stage estimates indicate Wal-Mart's profitability from population is lower than Kmart's or Target's, the net effect (captured by $\gamma^{\text {pop }}$ ) is still positive. The set estimates for the other market characteristics are generally neutral; that is, they cover both positive and negative values. It is therefore difficult to draw conclusions about these firms' preferences for income or household size, after controlling for the impact of high values of population. This is likely due to the relatively coarse market definition we have employed. However, pinning down the baseline impact of population does allow us to quantify the impact of own

\footnotetext{
${ }^{19}$ Note that the bounds recovered from the set-inference procedure are conservative in that they represent the outer envelope of values that the parameter can take for all possible values of the remaining parameters. Our results therefore imply that, no matter what value is taken by the vector of other parameters, log population always has a positive effect on profits. The same cannot be said of the other covariates.
} 
and rival stores in terms of required changes in population (the main driver of demand).

Table 4: Increase in Population Required to Offset or Induce Entry

\begin{tabular}{|c|l|ccc|}
\hline \hline Initial \# of Own Stores, Population & Change & Kmart & Target & Walmart \\
\hline Originally 1 own store, & $1 \rightarrow 2$ own stores & 18,001 & 19,329 & 27,353 \\
population of 50,000 & $1 \rightarrow 2$ rivals & 52,408 & 42,650 & 40,937 \\
\hline Originally 2 own stores, & $2 \rightarrow 3$ own stores & 26,509 & 30,233 & 41,980 \\
population of 150,000 & $2 \rightarrow 3$ rivals & 87,973 & 74,641 & 69,658 \\
\hline Originally 5 own stores, & $5 \rightarrow 6$ own stores & 31,543 & 37,422 & 51,863 \\
population of 450,000 & $5 \rightarrow 6$ rivals & 107,086 & 94,811 & 85,653 \\
\hline Originally 10 own stores, & $10 \rightarrow 11$ own stores & 36,903 & 45,533 & 64,211 \\
population of 1,200,000 & $10 \rightarrow 11$ rivals & 136,351 & 123,477 & 109,225 \\
\hline
\end{tabular}

Table 4 presents the increase in population required to offset the entry of a rival store or induce the entry of another own store, evaluated for a few representative market configurations. The local chain effect is again reflected in the wedge between these two quantities. For the smallest market category, an additional 18,000 to 27,000 people are needed to induce these firms to build another store, which brackets the "back of the envelope" minimum efficient scale calculation discussed in Section 2. Note that this "required" level of population increases with market size, as discount stores likely face more and better substitutes in larger markets.

\section{The Role of Unobserved Location Attributes}

One of the key advantages of our modeling strategy is the ability to account for spatial unobservables, which we denote by $\xi_{j}$, that might be important determinants of firms' siting decisions. If firms site more stores in locations with attractive unobservables, but those unobservables are ignored in estimation, the researcher could mistake them for positive spatial spillovers (or will at least understate the role of business stealing effects - both between a firm's own stores and with those of its rivals). In order to illustrate the important role played by these unobservables, we re-estimate the model used above under the restriction that $\xi_{j}=0 \forall j$. All parameters can therefore be estimated in a single-stage using the maximum score procedure. To accommodate the kinked impact of population on store counts (recall the spline figures in Section 2), we allow the baseline impact of population (on WalMart's profits) in the model without $\xi$ to follow a simple spline with a knot at $\ln (50,000)$ roughly the population required to support a second store (see Section 2). Note that we did 
not need to do this for the main specification, as the fixed effects could accommodate this (or any other) feature of the data non-parametrically in the first stage. This is an additional benefit of our differencing approach to estimation.

Column II of Table 1 reports these results. The effects of competition from rivals are all biased towards zero. Rival stores are clearly proxying for unobserved spikes in the relative desirability of particular markets. The coefficient on the distance to the nearest distribution center is biased away from zero, implying that distance to DC and unobserved characteristics are negatively correlated. This suggests that firms site their distribution centers closer to the unobservably 'good' places to locate a store, an intuitive result. Finally, the own effects are also biased toward zero, but this again requires an analysis of the marginal effects since it involves three parameters. Table 9 (in Appendix A) repeats the marginal effect analysis presented in Table 2, focusing exclusively on own effects and presenting results both with and without $\xi$. As with the rival effects, we find that net chain effects are biased toward zero when one ignores the presence of market-level unobservables. Without $\xi$, the model confounds unobserved features of the market which are attractive to all three firms with a desire to cluster their stores.

Finally, the importance of unobservable characteristics can also be seen by comparing the value of the score function under different specifications. When the unobserved market characteristic is ignored (Column II), the estimator correctly satisfies approximately $74 \%$ of the sampled inequalities. This score jumps to $97 \%$ when the unobservable is accounted for, highlighting the role of common market-level unobservables in explaining entry behavior.

\section{Robustness Check: Estimation Based on Only Recent Store Placement}

While the inherent non-stationarity of the discount store industry makes a fully dynamic model of retail competition intractable using current methods, we can examine the robustness of our static framework by focusing on recently placed stores, taking the pre-existing locations as given. In particular, we re-estimate the model using only those stores sited after 2000 (the earliest date for which would could obtain data from Trade Dimensions). As noted earlier, Kmart has not opened any stores in past decade, so this part of the analysis will focus only on the actions of Wal-Mart and Target (although we do condition on the presence of existing Kmart stores). Both Wal-Mart and Target were quite active during 
this period (2000-2006), with Wal-Mart adding 760 new stores in 294 markets and Target adding 471 new stores in 168 markets.

The estimates from this specification are reported in Column III of Table 1. The own and rival effects are qualitatively similar to those of the full model, providing some degree of cross-validation. The coefficients and marginal effects (not reported) are all larger in magnitude. This is to be expected since the most recently placed stores are constrained by the fact that many of the best locations were already filled in prior periods. Similarly, the coefficient on distance to the nearest distribution center is now positive and significant, reflecting the fact that the newest stores are mostly on the periphery of the existing networks.

\subsection{Counterfactual: Illustrating the Role of Positive Spillovers within a Chain}

The previous section characterized the relative magnitude of rival and own (chain) effects using comparative statics. We now address the full equilibrium implications of the local chain effect though a counterfactual exercise. In particular, we use the first order conditions described in Section 3.2 to solve for the new configuration that obtains when local chain effects are "turned off". This exercise highlights two important sources of flexibility in our modeling strategy. First, we can accommodate any number of firms, while previous approaches were restricted to either a single firm (Holmes (2008)) or a pair of firms (Jia (2008), Nishida (2008)). Second, since our model does not require that spatial spillovers be positive, we can handle cases (such as this) in which business stealing overwhelms local chain effects on net. To capture the equilibrium impact of local chain effects, we construct a counterfactual scenario in which each firm views its other stores symmetrically to those of its rivals when siting a new store. In other words, the chain effect no longer dampens the impact of increasing the portfolio of own stores. The difference in the resulting store distributions quantifies the local network effect. ${ }^{20}$

To simulate this counterfactual scenario, we return to the set of inequalities described in Section 3.2, which are based on the assumption that each firm equates the marginal

\footnotetext{
${ }^{20}$ In practice, the difference between this result and reality may understate the effect of agglomeration effects, because the business stealing effects associated with rivals' stores are likely to be smaller than the business stealing effects associated with a firm's own stores, as its own stores will be closer substitutes for one another. In this counterfactual, we have set $\beta_{\text {own }}=\beta_{\text {other }}$ even though eliminating all agglomerative benefits would likely imply $\beta_{\text {own }}<\beta_{\text {other }}$.
} 
profitability of the last store in each market up to an integer constraint. Recall from Inequalities (5) and (6) that this implies:

$$
\begin{array}{ll}
\psi_{2, j}^{f}\left(N_{j}^{f}+1, N_{j}^{f} ; \boldsymbol{\beta}\right)+\theta_{j}<c^{f} \leq \psi_{1, j}^{f}\left(N_{j}^{f}, N_{j}^{f} ; \boldsymbol{\beta}\right)+\theta_{j}, & \text { if } N_{j}^{f}>0 \\
\psi_{2, j}^{f}\left(N_{j}^{f}+1, N_{j}^{f} ; \boldsymbol{\beta}\right)+\theta_{j}<c^{f}, & \text { if } N_{j}^{f}=0 ; \forall j, f
\end{array}
$$

In general, we can construct counterfactual equilibria by solving for the store configurations that satisfy these inequalities under alternative values of the $\boldsymbol{\beta}$ parameters (or any of the covariates). ${ }^{21}$ However, two complications arise in practice. First, there may be more than one set of configurations that satisfy this set of inequalities, reflecting a multiplicity of equilibria in the underlying game. For example, consider a market that initially has two Target stores and two Wal-Mart stores. Under the counterfactual scenario, without the benefits arising from being part of a chain, one store may exit, but that store could either be a Target or a Wal-Mart store. In the exercises that follow, we will resolve this problem using a selection rule. Second, because there are only three players, we could only bound the values of $c^{f}$ and $\theta_{j}$ in estimation, creating an additional source of slackness. The second source of slackness implies that any counterfactual equilibrium configuration $\left(N^{K}, N^{T}, N^{W}\right)$ must satisfy a set of inequalities that takes these intervals into account:

$$
\begin{array}{ll}
\psi_{2, j}^{f}+\theta_{j, \text { low }}<c_{\text {high }}^{f} \text { and } c_{\text {low }}^{f} \leq \psi_{1, j}^{f}+\theta_{j, h i g h}, & \text { if } N_{j}^{f}>0 \\
\psi_{2, j}^{f}+\theta_{j, \text { low }}<c_{\text {high }}^{f}, & \text { if } N_{j}^{f}=0 ; \forall j, f
\end{array}
$$

Under a counterfactual scenario that imagines each store's profit is affected equally by rival stores and by stores in the same chain (i.e., no agglomeration benefits), the configuration of stores will satisfy the above inequalities with $\beta^{f, \text { Own }}=\hat{\beta}^{f, \text { Other }}$ and $\beta^{T, \text { Own } 2}=\beta^{T, \text { Own } 3}=$ 0 . To find these configurations, we first solve for the real-valued choices $\left(N^{K}, N^{T}, N^{W}\right)$ that

\footnotetext{
${ }^{21}$ Here we have held the marginal profitability of the last store, $c^{f}$ constant for each firm. In essence, this assumes that the firm's access to capital remains fixed in the counterfactual scenario. Because stores themselves become more or less profitable in the counterfactual scenario, the total number of store built will change. An alternative approach would have been to hold the total number of stores owned by each firm fixed, and allow them to allocate those stores so that the marginal profitability of the last store is the same across locations, but takes on a different value than the $c^{f}$ we observe.

Without a specific model for how firms construct their distribution networks, we cannot simulate how these networks might change under different counterfactual scenarios. Here, we have held these networks fixed. However, the effect of distance to the nearest distribution center was not significant in our estimates, so we cannot predict whether and how this restriction influences our results.
} 
exactly solve a related system of equalities formed by using values of $c^{f}$ and $\theta_{j}$ at the midpoints of their respective intervals. We then search over a grid of discrete values near this real-valued solution. ${ }^{22}$ For example, if the real-valued solution has 0.3 Kmart stores, 1.4 Target stores, and 3.2 Wal-Mart stores, we search over the 8 possible configurations where Kmart has 0 or 1 stores, Target has 1 or 2 stores, and Wal-Mart has 3 or 4 stores. This algorithm succeeds in finding at least one configuration of stores that satisfies all inequalities in the markets we consider. ${ }^{23}$

Not surprisingly, in many markets there are several configurations of stores that can satisfy all $(2 \times$ \# firms) equalities. In the results presented below, we have selected the configuration of stores that is closest to the original observed equilibrium configuration. ${ }^{24}$ Ties in this measure are broken by favoring Wal-Mart (allowing it to expand the most or contract the least), followed by Target, then Kmart. The results are qualitatively similar when using alternative equilibrium selection rules.

Table 5 summarizes the results of this counterfactual simulation. When we eliminate the local benefits associated with being a chain, leaving only the congestion or business stealing effect, all three firms either maintain or reduce the number of stores they operate. In over half of the small markets (those with population less than 200,000), the observed configuration of stores still satisfies the new set of inequalities. These are markets where firms have one or two stores at most, where firms are not currently taking much advantage of positive spillovers and removing these benefits does not change siting behavior. However, nationwide the number of stores falls by $47 \%$ from 5,886 to 2,761 stores in the markets considered. Kmart's reduction is especially dramatic, as it exits 522 markets entirely. This suggests that their presence in many markets is driven by the ability to take advantage of local chain economies. The same can be said for Target, which experiences significant declines especially in the metropolitan areas with populations' over 1 million. These seem to be precisely the markets where Target currently takes the most advantage of agglomeration.

\footnotetext{
${ }^{22}$ The task of searching for configurations that satisfy all inequalities is simplified considerably by the specification of our model. Because there are no cross-market spillovers, the $(2 \times \#$ firms $)$ inequalities can be solved separately for each of the $L$ locations, rather than solving $(2 \times \#$ firms $\times L)$ inequalities simultaneously.

${ }^{23}$ We simulate the counterfactual equilibria for 1344 of the 1351 markets, dropping the 7 markets where the market-specific $\theta_{j}$ intervals that satisfy the individual firms' inequalities fail to overlap. See footnote 16 in Section 3.2.

${ }^{24}$ We define the "closest" equilibrium as the one with the minimum absolute difference between counterfactual and observed numbers of stores.
} 
Table 5: Counterfactual 1: Change in Number of Stores

\begin{tabular}{|c|c|c|c|c|c|c|c|c|}
\hline \multirow[t]{2}{*}{ Type of Market } & \multirow[t]{2}{*}{ \# } & \multicolumn{2}{|c|}{ Population } & \multirow{2}{*}{$\begin{array}{l}\text { Markets with } \\
\text { No Change }\end{array}$} & \multicolumn{4}{|c|}{ Average Change in } \\
\hline & & $\min$ & $\max$ & & Total Stores & Kmart & Target & Wal-Mart \\
\hline \multirow[t]{2}{*}{ Non-Metropolitan $\dagger$} & 993 & 3,643 & 193,035 & 683 & -0.34 & -0.27 & -0.01 & -0.06 \\
\hline & & & & & $-15.3 \%$ & $-88.1 \%$ & $-12.7 \%$ & $-3.0 \%$ \\
\hline \multirow[t]{2}{*}{ Small Metropolitan } & 159 & 55,289 & 198,848 & 5 & -1.36 & -0.93 & -0.15 & -0.28 \\
\hline & & & & & $-37.2 \%$ & $-98.8 \%$ & $-17.3 \%$ & $-10.1 \%$ \\
\hline \multirow[t]{2}{*}{ Metro $>200,000$} & 101 & 202,902 & 497,640 & 0 & -3.82 & -1.84 & -0.60 & -1.38 \\
\hline & & & & & $-51.0 \%$ & $-99.1 \%$ & $-33.2 \%$ & $-27.9 \%$ \\
\hline \multirow[t]{2}{*}{ Metro $>500,000$} & 45 & 512,138 & 994,551 & 0 & -9.36 & -3.76 & -2.60 & -3.00 \\
\hline & & & & & $-61.3 \%$ & $-100.0 \%$ & $-61.2 \%$ & $-36.1 \%$ \\
\hline \multirow[t]{2}{*}{ Metro $>1$ million } & 46 & $1,024,678$ & 18.8 million & 0 & -38.28 & -10.67 & -15.57 & -12.04 \\
\hline & & & & & $-70.1 \%$ & $-95.6 \%$ & $-82.5 \%$ & $-47.9 \%$ \\
\hline \multirow[t]{2}{*}{ Total } & 1344 & 3643 & 18.8 million & 688 & -2.33 & -0.94 & -0.69 & -0.70 \\
\hline & & & & & $-24.0 \%$ & $-93.4 \%$ & $-33.9 \%$ & $-8.5 \%$ \\
\hline
\end{tabular}

† Includes 554 micropolitan statistical areas and 439 isolated counties.

Figures in italics represent the mean of the percentage declines for each firm in each market.

\section{Conclusions}

Many of the most important sectors in the U.S. economy are characterized by a small number of firms making many interlinked entry decisions over a large choice set (i.e., a high-dimension network game). This market structure creates considerable difficulty for the economic modeling of entry behavior. In particular, the large number of possible configurations available to firms rules out using the traditional likelihood-based approaches (assuming either complete or incomplete information) to modeling games. In this paper, we propose an alternative approach based on profit inequalities (Pakes et al. (2006), Bajari et al. (2007)). Basing identification only on the premise that the firm chose its best possible configuration (given the equilibrium play of its rivals), this approach avoids ever having to solve for an equilibrium or even specify a selection mechanism. Nor does it ever require that we solve for the probability of seeing each of an almost uncountable number of configurations. Implementing this estimator is complicated by the fact that we need to control for the effect on entry of market attributes, many of which are unobserved. We show how this can be accomplished by using the logic of a difference-in-differences estimator nested inside these inequalities.

We conclude by noting two limitations of our analysis (or, alternatively, opportunities 
for future research). First, we model entry behavior as a static game. Even with the methods described above, this is a challenging exercise, but it is clearly ignores the dynamics that unfolded over the long time frame over which Target, Kmart, and Wal-Mart built their stores. Adding dynamics while maintaining our full strategic environment, focus on distribution network, and choice set definition poses serious challenges. Second, we are forced to restrict our structural errors to only allow for a market-level unobservable that is common across all firms. It would be desirable to allow firms to have heterogeneous preferences for market features that are unobserved by the econometrician. Doing so in the present context would, however, invalidate our "double difference" approach to handling market-level unobservables. 


\section{References}

[1] Ackerberg, D. and G. Gowrisankaran. (2007). "Quantifying Equilibrium Network Externalities in the ACH Banking Industry," RAND Journal of Economics, 37(3): 738761.

[2] Andrews, D., S. Berry, and P. Jia. (2004). "Confidence Regions for Parameters in Discrete Games with Multiple Equilibria," Working Paper: Yale University.

[3] Aguirregabiria, V. and P. Mira. (2007). "Sequential estimation of dynamic discrete games," Econometrica, 75(1): 1-53.

[4] Bajari, P., L. Benkard, and J. Levin (2007). "Estimating dynamic models of imperfect competition," Econometrica, 75(5): 1331-1370.

[5] Bajari, P. and J. Fox (2009). "Complementarities and Collusion in an FCC Spectrum Auction," Working Paper: University of Chicago.

[6] Bajari, P., J. Fox, and S. Ryan (2008). "Evaluating Wireless Carrier Consolidation Using Semiparametric Demand Estimation," Quantitative Marketing and Economics, 6(4): 299-338.

[7] Bajari, P., H. Hong, J. Krainer, and D. Nekipelov (2006). "Estimating Static Models of Strategic Interactions," Forthcoming in the Journal of Business and Economic Statistics.

[8] Bajari, P., H. Hong, and S. Ryan (2009). "Identification and Estimation of a Discrete Game of Complete Information," Forthcoming in Econometrica.

[9] Basker, E. (2005). "Job creation or destruction? Labor market effects of Wal-Mart expansion," Review of Economics and Statistics, 87: 174-183.

[10] Basker, E. (2007). "The Causes and Consequences of Wal-Mart's Growth," Journal of Economic Perspectives, 21(3): 177-198. 
[11] Beresteanu, A., I. Molchanov, and F. Molinari (2009). "Sharp Identification Regions in Models with Convex Predictions: Games, Individual Choice, and Incomplete Data, " Cenmap Working Paper \#CPW27/09.

[12] Beresteanu, A. and F. Molinari (2008). "Asymptotic Properties for a Class of Partially Identified Models, " Econometrica, 76(4): 763-814.

[13] Berry, S. (1992). "Estimation of a Model of Entry in the Airline Industry," Econometrica, 60(4): 889-917.

[14] Berry S. (1994). "Estimating Discrete Choice Models of Product Differentiation," RAND Journal of Economics, 25(2): 242-262.

[15] Berry, S., J. Levinsohn, and A. Pakes (1995). "Automobile Prices in Market Equilibrium," Econometrica, 63(4): 841-890.

[16] Bresnahan, T. and P. Reiss (1990). "Entry in Monopoly Markets," Review of Economic Studies, 57(4): 531-553.

[17] Bresnahan, T. and P. Reiss (1991). "Entry and Competition in Concentrated Markets," Journal of Political Economy, 99(5): 977-1009.

[18] Ciliberto, F. and E. Tamer (2009). "Market Structure and Multiple Equilibria in Airline Markets," Econometrica, 77(6): 1791-1828.

[19] Ellickson, P. (2007). "Does Sutton Apply to Supermarkets?," RAND Journal of Economics, 38(1): 43-59.

[20] Fox, J. (2006). "Estimating Matching Games with Transfers," Working Paper: University of Chicago.

[21] Fox, J. (2007). "Semiparametric Estimation of Multinomial Discrete Choice Models Using a Subset of Choices," RAND Journal of Economics, 38(4): 1002-1019.

[22] Han, A. (1987). "Nonparametric Analysis of a Generalized Regression Model: The Maximum Rank Correlation Estimator," Journal of Econometrics, 35(2-3): 303-316. 
[23] Hausman, J. and E. Leibtag (2005). "Consumer Benefits from Increased Competition in Shopping Outlets: Measuring the Effect of Wal-Mart," NBER Working Paper No. 11809.

[24] Holmes, T. (2008). "The Diffusion of Wal-Mart and Economies of Density," Working Paper: University of Minnesota.

[25] Jia, P. (2008). "What Happens When Wal-Mart Comes to Town: An Empirical Analysis of the Discount Retail Industry," Econometrica, 76(6): 1263-1316.

[26] Manski, C. (1975). "Maximum Score Estimation of the Stochastic Utility Model of Choice," Journal of Econometrics, 3(3): 205-228.

[27] Manski, C. (1985). "Semiparametric Analysis of Discrete Response," Journal of Econometrics, 27(3): 313-333.

[28] Manski, C. and E. Tamer (2002). "Inference on Regressions with Interval Data on a Regressor or Outcome," Econometrica, 70(2): 519-546.

[29] Mazzeo, M. (2002). "Product Choice and Oligopoly Market Structure," RAND Journal of Economics, 33(2): 221-242.

[30] Neumark, D., J. Zhang, and S. Ciccarella (2008). "The Effects of Wal-Mart on Local Labor Markets," Journal of Urban Economics, 63(3): 405-430.

[31] Nishida, M. (2008). "Estimating a Model of Strategic Store-Network Choice," Working Paper: Johns Hopkins University.

[32] Pakes, A. (2008). "Theory and Empirical Work on Imperfectly Competitive Markets," Working Paper: Harvard University.

[33] Pakes, A., M. Ostrovsky, and S. Berry. (2007). "Simple estimators for the parameters of discrete dynamic games (with entry-exit examples)," RAND Journal of Economics, 38(2): 373-399.

[34] Pakes, A., J. Porter, K. Ho, and J. Ishii (2006). "Moment Inequalities and Their Application," Working Paper: Harvard University. 
[35] Pesendorfer M. and P. Schmidt-Dengler. (2008). "Asymptotic least squares estimators for dynamic games," Review of Economic Studies, 75(3): 901-928.

[36] Seim, K. (2006). "An Empirical Model of Firm Entry with Endogenous Product-Type Choices," RAND Journal of Economics, 37(3): 619-640.

[37] Smith, H. (2004). "Supermarket Choice and Supermarket Competition in Market Equilibrium," Review of Economic Studies, 71(1): 235-265.

[38] Sinnott, R.W. (1984). "Virtues of the Haversine," Sky and Telescope, 68(2): 159.

[39] Tamer, E. (2003). "Incomplete Simultaneous Discrete Response Model with Multiple Equilibria," Review of Economic Studies, 70(1): 147-165.

[40] Zhu, T., and V. Singh. (2009). "Spatial Competition with Endogenous Location Choices - An Application to Discount Retailing," Quantitative Marketing and Economics, 7(1): 1-35.

[41] Zhu, T., V. Singh, and M. Manuszak. (2009). "Market Structure and Competition in the Retail Discount Industry," Journal of Marketing Research, 46: 453-466. 


\section{A Additional Description of Data}

The data for the discount store industry are taken primarily from the Trade Dimensions Retail Tenant Database for 2006. This proprietary dataset contains all 6,150 Wal-Mart, Kmart, and Target stores in operation in the continental United States as of August 2006. These include both pure discount stores that carry general merchandise and newer supercenter formats that also carry full grocery lines. ${ }^{25}$ Because of the additional difficulty in modeling a firm's choice of store format, we do not distinguish between these two types of stores in our current application.

Stores are assigned to markets based on the county in which they are located. Where possible, ${ }^{26}$ adjacent counties are grouped together into single markets according to the 2005 Census definitions for CBSAs. These statistical areas contain an average of 1.9 counties and include both a core urban area and any adjacent counties that are closely linked economically and socially. Metropolitan areas are those with a core urban area with a population of at least 50,000, and micropolitan areas are those with a core urban area with a population from 10,000 to 50,000 .

We believe that using CBSA's to define markets is more appropriate than using counties alone since they typically define a more natural "shopping area" by grouping interrelated counties together. The same criticism that applies to using large counties (e.g., Los Angeles County) to measure markets also applies here - all stores in the largest metro areas probably do not compete equally with one another. However, this broad market definition allows us to capture any positive supply-side spillovers that may potentially occur between stores of the same chain located in the same MSA.

We have collected demographic and economic data on each market from the U.S. Census Bureau. The most recent population estimates at the CBSA and county levels are available from the Census Population Division for July 2006. Household median income and average household size are aggregated from the county level from the 2000 Census. We also include the percentage of the metro or micro area population that is located in an urban area,

\footnotetext{
${ }^{25}$ We exclude Sam's Club stores, owned by Wal-Mart, because these warehouse clubs do not compete directly with Kmart and Target stores. Furthermore, they are served by separate distribution facilities from those that serve Wal-Mart stores.

${ }^{26}$ A total of 439 counties with discount stores are relatively isolated and are not included as part of any Census-defined CBSA. These counties are included as individual markets in our estimation.
} 
collected from the website of the Missouri Census Data Center.

The Trade Dimensions database contains the locations of each of the 113 distribution centers that serve the stores in our analysis. Wal-Mart is vertically-integrated, owning all 70 distribution centers that supply its stores. Kmart and Target operate most of the distribution centers that supply their stores, 13 and 24 centers, respectively. However, a small number of their stores rely on third-party distributors. We include the locations of one Merchants Distributors center and five SuperValu distribution centers that serve Kmart and Target stores, respectively. Using the Haversine formula, we calculate the distance from the population-weighted centroid of each market to the county of the closest distribution center for each firm.

Summary statistics for these markets are provided in Tables 6 and 7. Of the 1351 markets that contain at least one discount store, 358 are metro areas, 554 are micro areas, and 439 are counties outside a metro or micro area. Population estimates for 2006 range from 3,643 (in Norton, VA) to over 18.8 million (in New York-Northern New Jersey-Long Island). The number of discount stores per market ranges from 1 to 161 stores (in the Chicago market), but this distribution is highly skewed. The median number of stores per market is 1 , and $75 \%$ of markets have 3 or fewer stores. Table 8 documents the expansion of Target and Wal-Mart between 2000 and 2006. Kmart did not add stores in any markets during this time period; instead it closed 710 stores following its bankruptcy in early 2002 . 
Table 6: Summary Statistics by Market

\begin{tabular}{|lrrrrr|}
\hline \hline & Obs & Mean & Std. Dev. & Min & Max \\
\hline Population in 2006 & 1351 & 213,424 & 860,138 & 3,643 & $18,818,536$ \\
Land area (in sq. miles) & 1351 & $1,448.41$ & $1,961.37$ & 5.67 & $27,259.87$ \\
Population density & 1351 & 119.23 & 199.60 & 1.76 & $2,797.94$ \\
Average household size & 1351 & 2.53 & 0.18 & 2.18 & 3.75 \\
Median income & 1351 & $\$ 34,742$ & $\$ 6,816$ & $\$ 16,271$ & $\$ 73,874$ \\
Percentage urban population & 1351 & 0.52 & 0.22 & 0 & 1 \\
Metropolitan Statistical Area & 1351 & 0.26 & 0.44 & 0 & 1 \\
Micropolitan Statistical Area & 1351 & 0.41 & 0.49 & 0 & 1 \\
Northeast & 1351 & 0.08 & 0.28 & 0 & 1 \\
Midwest & 1351 & 0.32 & 0.46 & 0 & 1 \\
South & 1351 & 0.46 & 0.50 & 0 & 1 \\
West & 1351 & 0.14 & 0.34 & 0 & 1 \\
Distance to closest Kmart DC (in miles) & 1351 & 192.08 & 113.45 & 0.14 & 661.64 \\
Distance to closest Target DC (in miles) & 1351 & 144.20 & 96.81 & 0.70 & 682.44 \\
Distance to closest Wal-Mart DC (in miles) & 1351 & 90.53 & 62.76 & 0.75 & 507.60 \\
Number of discount stores & 1351 & 4.55 & 11.84 & 1 & 161 \\
Number of Kmart stores & 1351 & 1.01 & 2.89 & 0 & 43 \\
Number of Target stores & 1351 & 1.07 & 4.53 & 0 & 72 \\
Number of Wal-Mart stores & 1351 & 2.48 & 5.34 & 0 & 85 \\
\hline
\end{tabular}

Table 7: Summary Statistics by Store

\begin{tabular}{|c|c|c|c|c|c|c|}
\hline & \multicolumn{2}{|c|}{ Kmart } & \multicolumn{2}{|c|}{ Target } & \multicolumn{2}{|c|}{ Wal-Mart } \\
\hline & Mean & Std. Dev. & Mean & Std. Dev. & Mean & Std. Dev. \\
\hline Population in 2006 & $2,254,909$ & $3,926,236$ & $3,523,082$ & $4,301,172$ & $1,671,212$ & $2,993,719$ \\
\hline Land area (in sq. miles) & 3515.56 & 3795.60 & 4922.78 & 4200.67 & 3417.85 & 3719.22 \\
\hline Population density & 513.46 & 634.61 & 700.23 & 717.17 & 371.05 & 495.78 \\
\hline Average household size & 2.56 & 0.20 & 2.62 & 0.20 & 2.57 & 0.19 \\
\hline Median income & $\$ 41,640.98$ & $\$ 7,578.02$ & $\$ 45,519.59$ & $\$ 7,475.11$ & $\$ 39,731.92$ & $\$ 8,038.29$ \\
\hline Percentage urban population & 0.76 & 0.20 & 0.86 & 0.13 & 0.70 & 0.23 \\
\hline Average Weekly Sales Volume & $\$ 241,942$ & $\$ 85,461$ & $\$ 670,149$ & $\$ 184,103$ & $\$ 991,846$ & $\$ 346,157$ \\
\hline Metropolitan Statistical Area & 0.78 & 0.42 & 0.95 & 0.21 & 0.68 & 0.47 \\
\hline Micropolitan Statistical Area & 0.17 & 0.38 & 0.04 & 0.20 & 0.19 & 0.39 \\
\hline Northeast & 0.18 & 0.38 & 0.12 & 0.33 & 0.11 & 0.32 \\
\hline Midwest & 0.31 & 0.46 & 0.28 & 0.45 & 0.25 & 0.43 \\
\hline South & 0.33 & 0.47 & 0.34 & 0.47 & 0.49 & 0.50 \\
\hline West & 0.18 & 0.39 & 0.26 & 0.44 & 0.15 & 0.36 \\
\hline Distance to HQ (in miles) & 713.24 & 567.09 & 913.92 & 428.08 & 695.32 & 368.72 \\
\hline $\begin{array}{l}\text { Distance to closest own DC } \\
\text { (in miles) }\end{array}$ & 153.17 & 121.57 & 117.83 & 95.08 & 75.93 & 52.57 \\
\hline Number of Stores & 13 & & & & & \\
\hline
\end{tabular}


Table 8: Comparing All Markets with Markets of Recently Placed Stores

\begin{tabular}{lcc}
\hline \hline Firm & Target & Walmart \\
\hline \# Stores & 1443 & 3345 \\
\# Markets & 381 & 1309 \\
\# Net New Stores & 471 & 760 \\
\# Locations with New Stores & 168 & 294
\end{tabular}

All Markets where Firm is Present

$\begin{array}{lcc}\text { Avg. Population } & 648,895 & 219,059 \\ \text { Percent Metro } & 83 \% & 27 \% \\ \text { Percent Micro } & 15 \% & 41 \%\end{array}$

Markets with Expansion Since 2000

Avg. Population 1,042,212 743,352

Percent Metro $\quad 91 \% \quad 70 \%$

Percent Micro $\quad 7 \% \quad 17 \%$

Table 9: Marginal Effect of $N^{\text {own }}$ on Own Per-Store Profits

\begin{tabular}{|clccc|}
\hline \hline Population & Model & Kmart & Target & Wal-Mart \\
\hline \multirow{5}{*}{50000} & with $\xi$ & -26.6 & -28.7 & -30.8 \\
& without $\xi$ & -7.5 & -15.3 & -9.2 \\
& & & & \\
\multirow{5}{*}{5000000} & with $\xi$ & -20.6 & -23.8 & -20.8 \\
& without $\xi$ & -6.0 & -15.6 & -6.3 \\
& with $\xi$ & -6.9 & -9.0 & -7.2 \\
& without $\xi$ & -2.0 & -7.0 & -1.7 \\
\multirow{2}{*}{200000} & with $\xi$ & -3.5 & -4.4 & -3.4 \\
& without $\xi$ & -1.0 & -3.0 & -0.4 \\
& & & & \\
& with $\xi$ & -1.8 & -2.2 & -2.3 \\
& without $\xi$ & -0.4 & -1.1 & -0.3 \\
& & & & \\
\hline
\end{tabular}

Marginal effects are evaluated at the number of stores the firm typically has in markets with the given level of population. For example, in markets with 50,000, Target and Kmart typically have just 1 store if they are present in the market, while Wal-Mart typically has 2 stores. The marginal effects are evaluated at these levels. 


\section{B Decomposing Market-Level Fixed Effects with Beresteanu and Molinari (2008)}

After recovering interval estimates of market-level fixed effects using the bounding procedure described in Section 3.2, we estimate the parameters for the best linear predictor of $\theta$ in the interval $\left[\theta_{L}, \theta_{U}\right]$ conditional on $X$. Suppose $X$ were to consist of two variables, $x_{1}$ and $x_{2}$. Then the population set-valued best linear predictor is defined as

$$
\Gamma=\left\{\left[\begin{array}{l}
\gamma_{1} \\
\gamma_{2}
\end{array}\right]:\left[\begin{array}{l}
\gamma_{1} \\
\gamma_{2}
\end{array}\right]=\left[\begin{array}{ll}
E\left(x_{1}^{2}\right) & E\left(x_{1} x_{2}\right) \\
E\left(x_{2} x_{1}\right) & E\left(x_{2}^{2}\right)
\end{array}\right]^{-1}\left[\begin{array}{l}
E\left(x_{1} \theta\right) \\
E\left(x_{2} \theta\right)
\end{array}\right], \theta \in\left[\theta_{L}, \theta_{U}\right]\right\}
$$

The estimate $\widehat{\Gamma}$ is obtained by using the sample analogs of the above expectations. The third term in brackets can simply be estimated by $\left[\frac{1}{J} X^{\prime} X\right]^{-1}$, which we will denote $\hat{\Sigma}^{-1}$. The last term in brackets can be written as $\mathbb{E}(G)$, where $G$ is a set-valued random variable reflecting all possible values of $X^{\prime} \theta$, given that $\theta$ is bounded by $\theta_{L}$ and $\theta_{U}$ :

$$
G=\left\{\left[\begin{array}{l}
x_{1} \theta \\
x_{2} \theta
\end{array}\right]: \theta \in\left[\theta_{L}, \theta_{U}\right]\right\}
$$

The sample analog to this expectation is given by the Minkowski average $\bar{G}_{J}=\frac{1}{J} \bigoplus_{j=1}^{J} G_{j}$. That is, for each observation $j, G_{j}$ is a line segment with endpoints $\left(x_{1, j} \theta_{L j}, x_{2, j} \theta_{L j}\right)$ and $\left(x_{1, j} \theta_{U j}, x_{2, j} \theta_{U j}\right)$. The Minkowski sum of $G_{j}$, from $j=1 . . J$, adds all these segments to form a many-sided polygon. Figure 4 illustrates the Minkowski sum of line segments corresponding to ranges of $\theta$ for two different markets (in our application, we would sum over all 1351 markets).

The polygon generated by the Minkowski sum is then transformed by $\left(X^{\prime} X\right)^{-1}$ to obtain an estimate of the set $\Gamma=\left[\gamma_{1}, \gamma_{2}\right]$. Therefore,

$$
\widehat{\Gamma}=\hat{\Sigma}^{-1} \bar{G}_{J}
$$

In general, if there are $K$ covariates in $X$, this estimated set $\widehat{\Gamma}$ will be a K-dimensional polytope. In our application, the $X$ variables include a constant term and various locationspecific characteristics, such as the natural log of population and median income, the average household size, the percent of the area's population living in urban areas, the population density, and regional dummies. It is computationally difficult (if not impossible) to Minkowski sum such a high-dimensional set-valued random variable. However, we can 

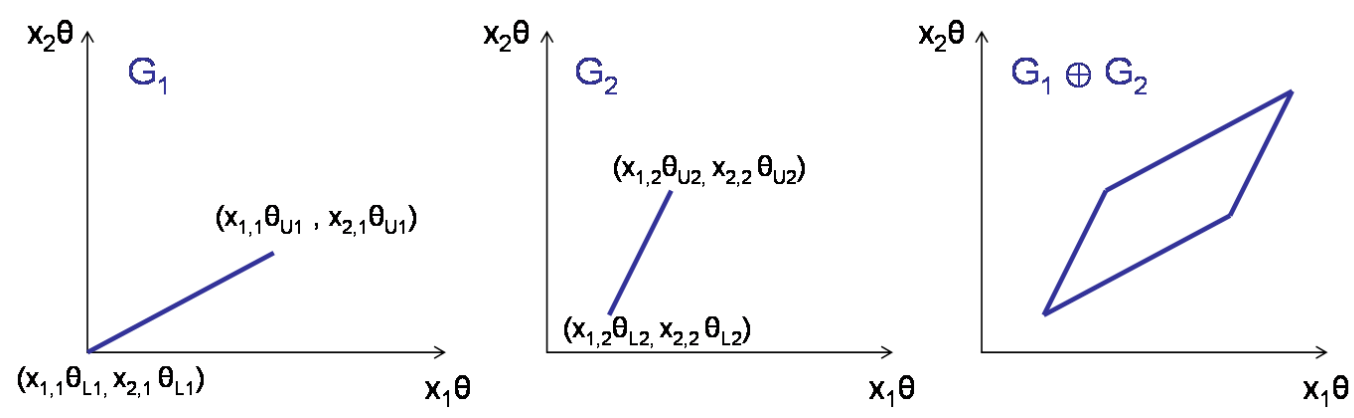

Figure 4: Minkowski Summation

estimate a subset of the parameters of the best linear predictor using the same logic as the Frisch-Waugh-Lovell Theorem for partial regression in point-identified models. For example, to estimate the set of possible coefficients on $\ln$ (population) and $\ln$ (median income), we first obtain the residuals from a linear regression of $\ln$ (population) on all other $X$ variables besides $\ln$ (median income) and the residuals from a linear regression of $\ln$ (median income) on all other $X$ variables besides $\ln$ (population). We then denote these $\tilde{x}_{1}$ and $\tilde{x}_{2}$ and use them in place of $x_{1}$ and $x_{2}$ above.

By the same partial regression logic, we can also estimate one-dimensional projections of the identification region. For example, the identification region of the best linear predictor coefficient for a single $\gamma_{k}$ can be estimated by the interval ${ }^{27}$

$$
\hat{\gamma}_{k}=\frac{1}{\frac{1}{J} \sum_{j=1}^{J} \tilde{x}_{k, j}^{2}}\left[\frac{1}{J} \sum_{j=1}^{J} \min \left\{\tilde{x}_{k, j} \theta_{L j}, \tilde{x}_{k, j} \theta_{U j}\right\}, \frac{1}{J} \sum_{j=1}^{J} \max \left\{\tilde{x}_{k, j} \theta_{L j}, \tilde{x}_{k, j} \theta_{U j}\right\}\right]
$$

where $\tilde{x}_{k, j}$ is the residual from the $j^{t h}$ observation in a regression of $x_{k}$ on the other $x_{-k}$, including the constant term.

For both the one-dimensional and two-dimensional projections, confidence sets can be formed by bootstrapping and computing the Hausdorff distance between the estimated set for the original sample and the estimated set for each bootstrapped sample, $H\left(\Gamma^{b}, \hat{\Gamma}\right) .^{28}$

\footnotetext{
${ }^{27}$ This simple result comes from Corollary 4.5 of Beresteanu and Molinari (2008).

${ }^{28} \mathrm{We}$ account for the estimation error from the first stage by incorporating the bootstrapped estimates of $\beta$ when forming the intervals for $\theta_{j}$.
} 
Under standard regularity conditions, Beresteanu and Molinari (2008) show that $r=$ $\sqrt{n} H\left(\Gamma^{b}, \hat{\Gamma}\right)$ is asymptotically normally distributed. Therefore, we can use the 95th percentile of the empirical distribution of $r$ to construct bounds on the collection of all sets that, when specified as the null hypothesis for the true value of the population identification region for $\Gamma$, cannot be rejected at a $95 \%$ confidence level. This is analogous to forming a $95 \%$ confidence interval for a point estimate. 